\title{
The formation of Tharsis on Mars: What the line-of-sight gravity is telling us
}

\author{
Jean-Pierre Williams, ${ }^{1}$ Francis Nimmo, ${ }^{2}$ William B. Moore, ${ }^{3}$ and David A. Paige ${ }^{3}$ \\ Received 27 November 2007; revised 26 June 2008; accepted 27 August 2008; published 31 October 2008.
}

[1] Line-of-sight (LOS) spacecraft acceleration profiles from the Radio Science

Experiment and topography from the Mars Orbiter Laser Altimeter (MOLA) instrument of the Mars Global Surveyor (MGS) are analyzed to estimate the effective elastic thickness $\left(T_{e}\right)$ for various regions of Tharsis. We identify a buried basin flanking the Thaumasia Highlands at the southeastern margin of Tharsis. Assuming that this basin results from lithospheric flexure from surface loading by the Thaumasia Highlands, we fit LOS profiles across the feature with a thin-shell, elastic flexure model and find the mountain belt to reflect a value of $T_{e} \sim 20 \mathrm{~km}$ consistent with a Noachian formation age. We also determine admittances from LOS profiles for five regions across Tharsis and fit them with theoretical admittances calculated using the flexural model. Crater density, surface density, and predominant surface age are found to vary systematically across Tharsis while $T_{e}$ does not. The highest surface density and lowest $T_{e}$ values are obtained for the western portion of Tharsis where crater densities are lowest. Our results imply the majority of the topographic rise was emplaced within the Noachian irrespective of the surface ages. Topographic loading and resurfacing (i.e., volcanic activity) persisted into the Amazonian while becoming increasingly confined to the western margin where the youngest surface ages are found and the eruptive style transitioned from effusive volcanism to shield-forming volcanism as $T_{e}$ increased.

Citation: Williams, J.-P., F. Nimmo, W. B. Moore, and D. A. Paige (2008), The formation of Tharsis on Mars: What the line-of-sight gravity is telling us, J. Geophys. Res., 113, E10011, doi:10.1029/2007JE003050.

\section{Introduction}

[2] Tharsis is a vast, complex topographic rise on Mars extending over 30 million square kilometers that dominates the western hemisphere of the planet [Scott and Tanaka, 1986]. The region has been the locus of large-scale volcanism that has endured for nearly the entirety of the planet's history resulting in pervasive fracturing of the crust from lithospheric loading by the voluminous intrusive and extrusive magmatic deposits [e.g., Anderson et al., 2001]. Its formation is almost certainly connected with the internal dynamics of the planet and how it dissipated its internal heat. Various mechanisms for the origin of Tharsis, based on gravity, topography, and analysis of the temporal and spatial distribution of tectonic features, have been proposed and can be classified into three general categories: external loading (constructional) [Solomon and Head, 1982; Willemann and Turcotte, 1982], domal uplift [Hartmann, 1973; Phillips et al., 1973; Carr, 1974; Plescia and

\footnotetext{
${ }^{1}$ Division of Geological and Planetary Sciences, California Institute of Technology, Pasadena, California, USA.

${ }^{2}$ Department of Earth Sciences, University of California, Santa Cruz, Santa Cruz, California, USA.

${ }^{3}$ Department of Earth and Space Sciences, University of California, Los Angeles, Los Angeles, California, USA.

Copyright 2008 by the American Geophysical Union. 0148-0227/08/2007JE003050\$09.00
}

Saunders, 1980], and isostatic compensation of buoyant, thickened crust [Wise et al., 1979a, 1979b; Sleep and Phillips, 1979, 1985]. The topography and gravity of Mars prior to Mars Global Surveyor (MGS) however, was of poor resolution and not well constrained [Esposito et al., 1992] and the origin, evolution, and internal structure of Tharsis remained largely unknown [Banerdt et al., 1992; Banerdt and Golombek, 2000].

[3] With MGS in a low ( $<400 \mathrm{~km}$ altitude), circular, nearpolar orbit [Albee et al., 2001], radio science solutions to the gravity field [Tyler et al., 2001] coupled with the topographic measurements provided by Mars Orbiter Laser Altimeter (MOLA) [Zuber et al., 1992], provide the opportunity to vastly improve our understanding of the internal structure of the planet [e.g., Zuber et al., 2000]. The increase in resolution and accuracy over all previous control point networks afforded by MGS provides an opportunity to reassess the predominant formation mechanism(s) and evolution of Tharsis.

[4] In section 2 of this article, we discuss the Thaumasia region of Tharsis, which we identify as a large $(\sim 2700 \mathrm{~km}$ diameter), volcanic plateau based on the interpretation of the topography, gravity, image data, and mapped geology. Modeling the flexural response of the lithosphere to an idealized volcanic load on the planet's surface, this study estimates the density and thickness of the volcanic load, and the effective elastic thickness, $T_{e}$. In section 3 , we utilize the admittance (the transfer function between the gravity and 


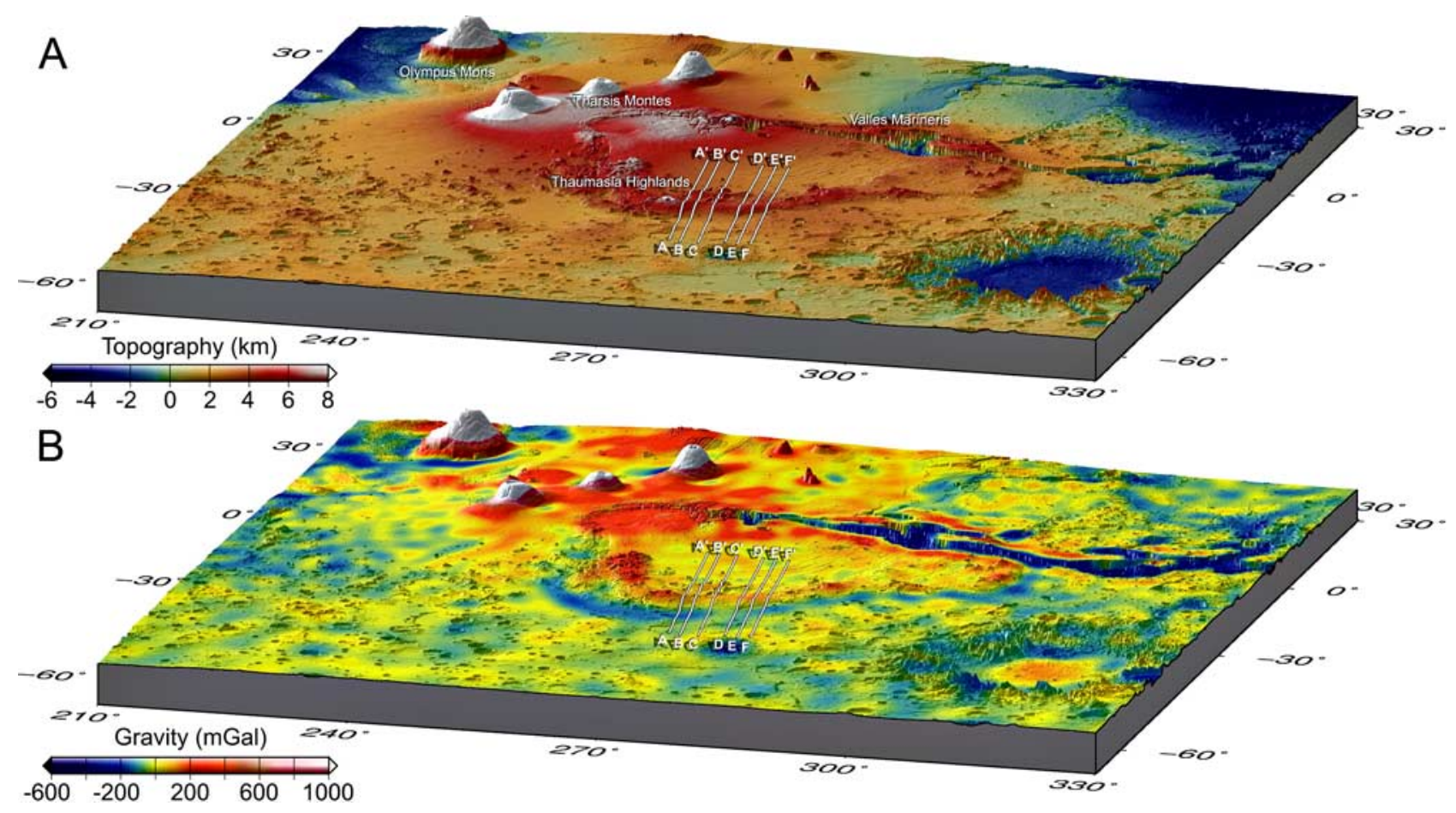

Figure 1. (A) Shaded relief map derived from gridded MOLA topography at a resolution of $1 / 32^{\circ}$ per pixel. (B) Shaded topographic relief map as in Figure 1A shaded with free-air gravity anomaly map derived from the MGS95J (JPL) Mars gravity model. The ground tracks of the six (A to F) LOS acceleration profiles are shown for reference and cross the Thaumasia Highlands, the arcuate mountain belt that forms the southern margin of the Thaumasia Plateau and represents the southern extent of the Tharsis region.

topography), derived from line-of-sight (LOS) acceleration profiles, to estimate values of $T_{e}$ for different regions of Tharsis. We compare and contrast best-fit estimates of $T_{e}$ for the southeastern half of Tharsis, the region containing Thaumasia, and the western half of Tharsis that contain the large shield volcanoes of Tharsis Montes and Olympus Mons, two regions which differ markedly in surface ages. The differing values of $T_{e}$ reflect the varying thermal state of the lithosphere at the time topographic loads were emplaced, allowing temporal comparisons of features and lithospheric provinces to be made.

\section{Thaumasia}

\subsection{Topography and Gravity Analysis}

[5] The MOLA data has made possible the recognition of the dominant contributors to the high-standing topography of Tharsis. The Thaumasia Highlands, consisting of a 4$5 \mathrm{~km}$ high arcuate mountain belt forming the southeast margin of Tharsis, represent the oldest preserved portion of Tharsis [Scott and Tanaka, 1986] and contain heavily cratered Noachian terrains that have survived resurfacing by younger volcanic flows presumably because of their high elevation. They bound a $2-4 \mathrm{~km}$ high interior plateau that includes Solis, Sinai, and Syria Planum, forming a $\sim 2700 \mathrm{~km}$ diameter quasi-circular region of elevated topography collectively referred to as the Thaumasia Plateau. The northern and western margin of the plateau has been heavily modified by the formation of the Valles Marineris canyon system and tectonic and volcanic activity centered on Syria Planum. In spite of this, the plateau has retained a quasi-circular planform.

[6] Topography from MOLA [Smith et al., 1999b] and the JPL gravity model MGS95J [Konopliv et al., 2006] were analyzed and maps of the Tharsis region were generated (Figure 1) where degree 95 corresponds to a Cartesian half wavelength of $\sim 110 \mathrm{~km}$. This analysis identified a negative free-air gravity anomaly flanking the Thaumasia Highlands immediately exterior to the Thaumasia Plateau in the

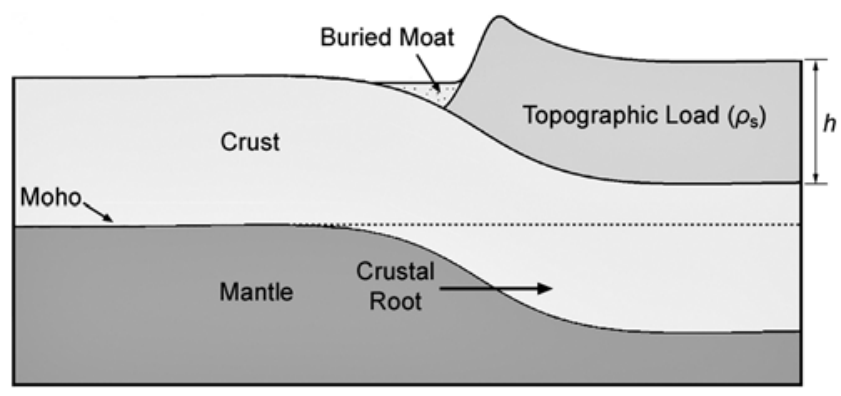

Figure 2. Cartoon depicting the interpretation of topography and gravity of the Thaumasia Highlands. The negative free-air gravity adjacent to the highlands is a consequence of lithospheric flexure from the topography. The gravity is then lower than predicted from the topography for the Thaumasia Highlands due to the deflection of the lithosphere and burial of the resulting flexural trench. 

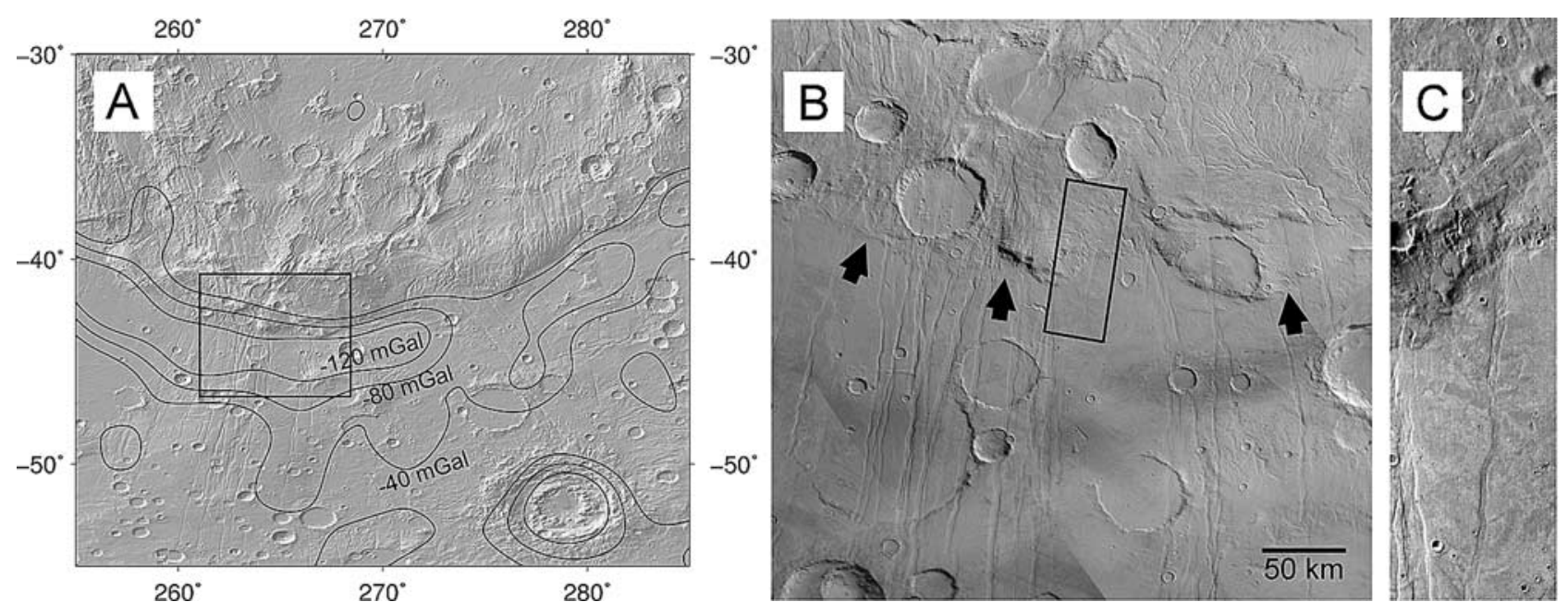

Figure 3. (A) MOLA shaded relief $\left(1 / 128^{\circ} \mathrm{pixel}^{-1}\right)$ of the Thaumasia Highlands (latitude -30 to $-50^{\circ} \mathrm{S}$, longitude 250 to $285^{\circ} \mathrm{E}$ ) with free-air gravity contours at $-40,-80$, and $-120 \mathrm{mGal}$. (B) Viking Orbiter VIS-A mosaic (images f063a05, f063a07, f063a08, f063a09, f532a13, f532a14, f532a15, and f532a16). (C) Approximately 30-km wide subframe of THEMIS daytime band 9 radiance image I14620007 [Christensen et al., 2004]. Box in Figure 3A outlines location of the mosaic. The contact between the Thaumasia Highlands and the younger trench filling materials that embay them is visible in both the MOLA data and the image data and correlates with the gravity anomaly (approximate location of contact denoted by black arrows). Numerous graben are evident (north to south trending linear features). Many truncate at the trench contact presumably because they have been buried while some propagate across the trench fill indicating that they were active after the trench was buried.

adjacent heavily cratered southern highlands. As there is no topographic expression associated with the gravity anomaly, this anomaly represents a density contrast in the crust or mantle and is interpreted in this work as the result of the burial of a flexural moat and a low-density crustal root created by the load emplaced on the planet's surface by the formation of Thaumasia.

[7] The wavelength dependence of flexural compensation will produce a gravity trough adjacent to the Thaumasia Highlands. Dombard et al. [2004] noted that troughs often occurred in the free-air gravity in the vicinity of shortwavelength topographic features. Any load, in this case the topographic plateau of Thaumasia, will impart a flexural signal in the gravity. Since the amount of compensation is wavelength-dependent, the long wavelength component of the topography is largely compensated. The edge of the plateau is dominated by power at short-wavelengths in the topography and therefore will experience more elastic support. This is shown schematically in Figure 2 where the resulting topography from an initially flat plateau retains the highest elevations at the plateau edge. The resulting Moho, initially flat in this case, is equivalent to the resulting deflection of the lithosphere. The flexural signal of a topographic load will extend beyond the edge of the feature, at a distance determined by $T_{e}$, and therefore will produce a gravity trough adjacent, and exterior, to its margin. The half width of the flexural depression, $x_{\circ}$, is $0.75 \pi \alpha$ where $\alpha^{4}=$ $4 D / \rho_{\mathrm{m}} g$ is the flexural parameter and is a function of $g$, the gravity, $\rho_{\mathrm{m}}$, the mantle density, and the flexural rigidity, $D=$ $E T_{e}^{3} / 12\left(1-\nu^{2}\right)$, where $E$ is Young's modulus and $\nu$ is Poisson's ratio [Turcotte and Schubert, 2002]. Taking the width of the gravity trough as $x_{\circ}=100-200 \mathrm{~km}$ yields $T_{e} \sim$ $22-57 \mathrm{~km}$ for $\rho_{\mathrm{m}}=3400 \mathrm{~kg} \mathrm{~m}^{-3}, E=100 \mathrm{GPa}$, and $\nu=$
0.25 . This is consistent, as will be shown, with the results obtained by fitting LOS profiles across the highlands.

\subsection{Geologic Evidence of the Moat}

[8] The buried flexural moat surrounding Thaumasia can be inferred from the correlation of the negative gravity anomaly with younger geologic units that are observed to embay the Thaumasia Highlands and bury large impact basins. The contact at the base of the Thaumasia Highlands is visible in maps derived from MOLA and image data (Figure 3). The materials comprising the immediate surrounding plains adjacent to the Highlands abut the mountains, exhibiting younger surface ages (Late Noachian/Early Hesperian) and lying stratigraphically above the units that are composed of the highlands (predominantly Early Noachian). Geologic units adapted from the geologic map of the western hemisphere of Mars by Scott and Tanaka [1986] (Figure 4) show that the region of the negative gravity anomaly corresponds approximately to geologic units with crater retention ages of Late Noachian and Early Hesperian (map units $\mathrm{Npl}_{2}, \mathrm{Hpl}_{3}, \mathrm{Hr}$, and $\mathrm{Hf}$ in the study of Scott and Tanaka [1986]). The geologic units in the Thaumasia Highlands and units extending beyond the negative gravity anomaly in the surrounding cratered plains are predominantly Early Noachian in age (map units Nplh, $\mathrm{Npl}_{1}$, Npld, $\mathrm{Nb}$, and Nf, in the study of Scott and Tanaka [1986]). This stratigraphic relationship constrains the formation of the flexural moat, and hence the formation of the Thaumasia Highlands, to the Early Noachian as the trench is filled by Late Noachian and Early Hesperian materials. The trench would have presented a sink for sediments, water, and volcanics. Rates of erosion and deposition were likely much higher during the Noachian than at present [Malin and 


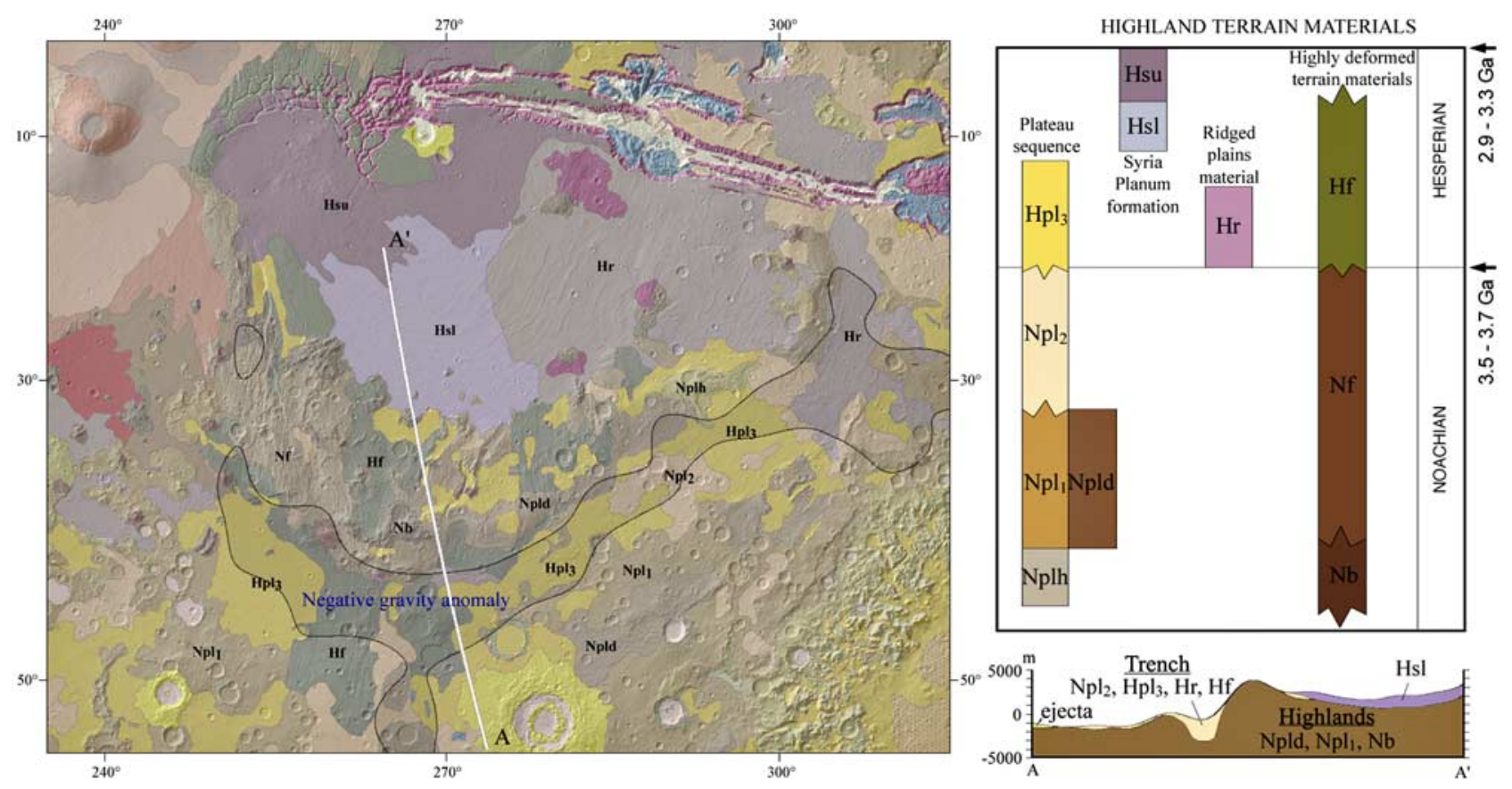

Figure 4. Map of MOLA derived shaded relief with geologic map adapted from the study of Scott and Tanaka [1986] and the free-air gravity contour for $-40 \mathrm{mGal}$ from reference gravity model MGS75D superposed. The stratigraphic definitions of geologic units in the vicinity of the Thaumasia Highlands are given on the right with approximate boundary ages from Hartmann and Neukum [2001]. At the bottom right, a simplified cross-section generated using a $1^{\circ}$ resolution MOLA profile corresponding with the ground track of profile $\left(\mathrm{A}-\mathrm{A}^{\prime}\right)$ used to depict the interpretation by this study of the relationship of the units originally mapped by Scott and Tanaka [1986]. For a full description and correlation of all the geologic units, see the study of Scott and Tanaka [1986].

Edgett, 2000]. The Thaumasia Highlands themselves, which are highly degraded and incised by valley networks, likely provided a source for infilling materials [Tanaka et al., 1998].

\subsection{LOS Acceleration Profiles}

[9] Raw line-of-sight (LOS) spacecraft accelerations from MGS indicate a mass deficit at Thaumasia relative to the acceleration that would be expected from topography alone [Williams et al., 2004]. This is further explored here using finite-amplitude topography and a wavelength-dependent flexural response function to determine the expected LOS acceleration for MGS spacecraft orbits that transect the Thaumasia Highlands (see Figure 1 for the orbit ground tracks used in this study). The gravity is related to the topography by

$$
g_{i l m}=4 \pi G \rho_{c}\left(\frac{l+1}{2 l+1}\right) h_{i l m}\left[1-\left(1-\frac{t_{c r}}{R}\right)^{l+2} \alpha_{l}\right]
$$

where $g_{i l m}$ and $h_{i l m}$ are spherical harmonic coefficients for gravity and topography respectively for degree $l$, order $m$. The crust density is $\rho_{c}, G$ is the gravitational constant, and $t_{c r}$ is the crust thickness. The function $\alpha_{l}$ is that of McGovern et al. [2002] modified from the formulation of Turcotte et al. [1981] and represents the degree of compensation for a given degree harmonic and is a function of the effective elastic thickness of the lithosphere, $T_{e}$, and the elastic constants: Young's modulus, $10^{11} \mathrm{~Pa}$, and Poisson's ratio,
0.25 . LOS accelerations, $g_{c}$, are then determined by [McKenzie and Nimmo, 1997]:

$$
g_{c}=\left[\frac{\partial U}{\partial r}(\hat{\mathbf{r}} \cdot \mathbf{d})+\frac{1}{r} \frac{\partial U}{\partial \theta}(\hat{\theta} \cdot \mathbf{d})+\frac{1}{r \sin \theta} \frac{\partial U}{\partial \varphi}(\hat{\phi} \cdot \mathbf{d})\right]_{r=R_{p}+a}
$$

where $U$ is the gravitational potential, $R_{p}$ is planetary radius, $a$ is the spacecraft altitude, $\hat{\mathbf{r}}, \hat{\boldsymbol{\theta}}$, and $\hat{\boldsymbol{\phi}}$ are the unit vectors pointing upward, southward, and eastward, respectively, and $\mathbf{d}$ is the line-of-sight vector.

[10] Tracks were selected from the GCO data (gravity calibration orbits spanning the period of 5 February 1999 to 1 March 1999) because their favorable viewing geometries provided high signal strength, Table 1 [Tyler et al., 2001; Lemoine et al., 2001]. An edge-on viewing geometry (Earth out-of-plane angle of $0^{\circ}$ ) maximizes the orbital velocity signal observed in the Doppler data. The Earth out-of-plane angle for the GCO orbits used in this study range from $\sim 2.5^{\circ}$ to $6^{\circ}$. As a result, the east-west vector component of the LOS acceleration is minimal, but radial and north-south components are large.

[11] Results for profile $\mathrm{A}-\mathrm{A}^{\prime}$ of Figure 1 are shown in Figure 5 for degrees 5-75 using a mantle density $3400 \mathrm{~kg}$ $\mathrm{m}^{-3}$, crust density $2900 \mathrm{~kg} \mathrm{~m}^{-3}$, crust thickness $100 \mathrm{~km}$, and elastic thickness $20 \mathrm{~km}$. The misfit across the Thaumasia Highlands and associated flexural moat $\left(\sim 34^{\circ}\right.$ to $46^{\circ} \mathrm{S}$ latitude) is large relative to the misfit elsewhere along the orbit. An exploration of the parameter space reveals that the misfit remains large for all values of $\rho_{c}, t_{c r}$, and $T_{e}$ and a 
Table 1. Spacecraft Orbits

\begin{tabular}{cccc}
\hline Profile & Ephemeris time $^{\mathrm{a}}$ & Longitude $^{\mathrm{b}}$ & Altitude $^{\mathrm{c}}$ \\
\hline A-A $^{\prime}$ & 1999-02-20T06:55:44.858 & 270.933 & $357.3-373.6$ \\
B-B & 1999-02-13T20:41:03.169 & 272.390 & $362.7-377.0$ \\
C-C $^{\prime}$ & 1999-02-14T02:43:54.328 & 274.512 & $407.1-417.9$ \\
D-D & 1999-02-09T23:53:01.904 & 277.588 & $405.9-421.1$ \\
E-E $^{\prime}$ & 1999-02-05T22:27:29.612 & 279.202 & $403.8-421.7$ \\
F-F $^{\prime}$ & $1999-03-05 T 21: 02: 09.337$ & 280.703 & $401.2-421.1$ \\
\hline
\end{tabular}

${ }^{a}$ Ephemeris time at the spacecraft at the beginning of the profile (date:hr:min:sec).

${ }^{\mathrm{b}}$ Value at start of orbit (most southern point of profile with ground track progressing north).

${ }^{\mathrm{c}}$ Altitude range in kilometer of orbit for $-50^{\circ} \mathrm{N}$ to $-20^{\circ} \mathrm{N}$ latitude.

simple loading model is not adequate as the correlation between topography and gravity is low. Likely causes for this are: erosion of the highlands, filling of the trench, and deposition of the Hesperian age volcanics within the plateau interior, all of which have the potential to alter the flexural signal and degrade the correlation between the topography and gravity limiting the usefulness of this approach.

[12] An alternate approach used here is a forward model. On the basis of the topographic configuration of Thaumasia, along with the inference of a buried flexural moat, we model Thaumasia as a large volcanic plateau, approximated as a disk load that is flexurally compensated to create the observed topographic and gravitational expression. The location of the disk is selected to coincide with the Thaumasia Plateau centered at $22^{\circ} \mathrm{S}, 269^{\circ} \mathrm{E}$ with a radius of $20^{\circ}$ placing the disk's edge at the periphery of the Thaumasia Highlands. Values of $T_{e}, \rho_{c}$, and disk thickness, $h$, are varied to fit the LOS acceleration profiles (Figure 1) with the goal of constraining the value of $T_{e}$ at the time the Thaumasia Highlands formed.

[13] The flexural response of the lithosphere to a topographic load remains fixed, and hence is "frozen in" when the loading occurs [Zuber et al., 2000; Watts and Burov, 2003]. Subsequent loading after the lithosphere thickness has changed and/or viscous relaxation will alter the flexural signal [Turcotte and Schubert, 2002]. As the value of $T_{e}$ of the Martian lithosphere is presumed to increase over time as the planet's heat flux diminishes, its value provides an estimate of the relative timing of loading events throughout its geologic history.
[14] Forward models used to fit spacecraft accelerations have been used in the past [e.g., Sjogren et al., 1975; Janle and Jannsen, 1986; Malin, 1986], for example, employed a similar model to estimate the density of the Martian north polar layered deposits. Using the LOS acceleration rather than the surface gravity has the advantage of providing a natural filter for removing ringing in the truncated harmonic series of the model as upward continuing the model gravity data attenuates power at smaller wavelengths, that is, it is a smoothing process.

[15] The LOS acceleration profiles however are not as intuitive to interpret as gridded gravity models. In general, perturbations in the spacecraft's acceleration have significant magnitudes in not only the radial component, but also the tangential component resulting from off-nadir features that exert an influence on the acceleration. The raw LOS data consists of values of residual MGS Doppler velocities relative to degrees 5-75 of the gravity model MGS75D [Yuan et al., 2001] as a function of position and time with the records being generally spaced $20 \mathrm{~s}$ apart. To obtain the full LOS acceleration, reference LOS accelerations from MGS75D are added back to the accelerations calculated from the residual Doppler velocities [McKenzie et al., 2002]. Prior to doing this, the reference accelerations from MGS75D were referenced to the geoid and a spatial filter was applied using a localizing window function with a value of 1 within an angular radius of 28 latitudinal degrees centered on Thaumasia and vanishing elsewhere. Further, the northern half of Thaumasia has been heavily modified by more recent geologic activity such as the formation of the Valles Marineris canyon system [Lucchitta et al., 1992] and the prolonged volcanic-tectonic activity of Syria Planum [Tanaka and Davis, 1988] that obfuscates the original symmetry of the plateau and hence imparts power in the acceleration not related to the formation of Thaumasia. We remove this power by mirroring the observed reference field about a longitudinal axis on the center latitude of Thaumasia $\left(22^{\circ} \mathrm{S}\right)$ and we only fit south of $22^{\circ} \mathrm{S}$.

[16] An alternate approach is to reconstruct the LOS accelerations using only the radial component of the reference field, i.e., only the first term on the right hand side of equation (2). This approach has the advantage that the reference field does not require any spatial filtering to isolate the signal of the highlands. The drawback is that the radial and tangential component of the LOS residual

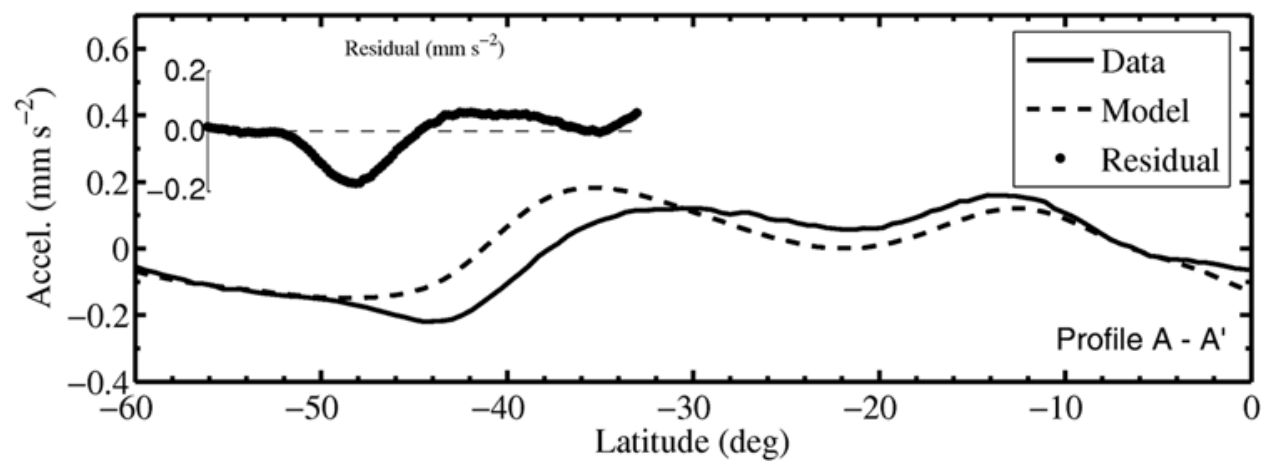

Figure 5. Observed and modeled LOS acceleration profile and the residual (inset) for ground track A- $\mathrm{A}^{\prime}$ for degrees $5-75$ using a $3400-\mathrm{kg} \mathrm{m}^{-3}$ mantle density, $2900-\mathrm{kg} \mathrm{m}^{-3}$ crust density, $100-\mathrm{km}$ crust thickness, and $20-\mathrm{km}$ elastic thickness in the model. Horizontal scale of inset is $-60^{\circ}$ to $0^{\circ}$ latitude. 


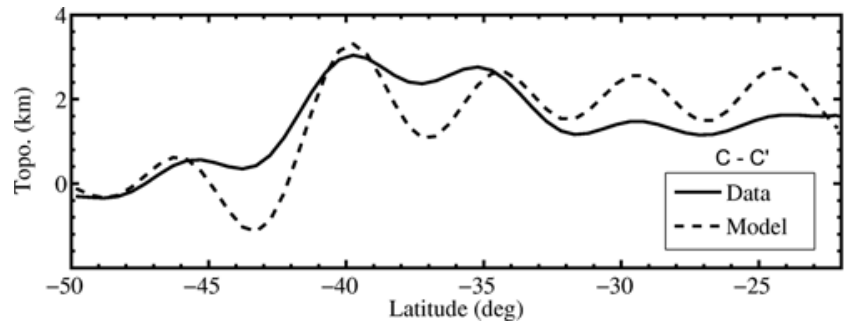

Figure 6. Observed topography and resulting best-fit model topography of representative profile $\left(C-\mathrm{C}^{\prime}\right)$ up to degree and order 75. Note that the short wavelength fluctuations result from ringing in the topographic expansion but are attenuated in the gravity derived from the topography at the height of the spacecraft.

cannot be separated, and thus the observed LOS acceleration has a tangential as well as a radial component, while the model acceleration has only a radial component. In the profiles used here, the residual is relatively small and thus the effect of the unmodeled tangential component is not significant. Minimizations using only the radial component of the model and reference fields result in very similar results to those in which all components are used. We report results based on the latter approach in the following section.

[17] The misfit between the modeled acceleration profile and the raw spacecraft acceleration profile is evaluated using the sum of squares of the residual, RSS. The initial disk thickness, $h$, disk density, $\rho_{s}$, and $T_{e}$ are varied to minimize RSS to determine a best-fit model. The model fit is further characterized with the $R^{2}$-statistic which quantifies the fraction of variance in the data explained by the model (for $R^{2}=0$ a model fit is no better than a horizontal line and approaches unity as a model approaches an exact fit).

\subsection{Results}

[18] The misfit between observed and calculated LOS profiles was calculated and best-fit parameters determined for six orbits in the latitudinal range of $-50^{\circ}$ to $-22^{\circ} \mathrm{N}$ (Figure 1). Misfit calculations were done for parameter ranges of $0-200 \mathrm{~km}$ for $T_{e}, 1-40 \mathrm{~km}$ for disk thickness, $h$, and $2000-3500 \mathrm{~kg} \mathrm{~m}^{-3}$ for $\rho_{s}$, with step sizes of $1 \mathrm{~km}$, $0.5 \mathrm{~km}$, and $10 \mathrm{~kg} \mathrm{~m}^{-3}$ respectively.

[19] There is generally a trade-off between the effective elastic thickness and the crustal thickness [e.g., Nimmo, 2002]. Constraints on the crustal thickness however are relatively weak and topography and gravity indicate the crust thickness is of great variability throughout Tharsis [Zuber et al., 2000]. Global admittance curves, neglecting the contributions of Olympus Mons and the Tharsis volcanoes, indicate a global compensation depth of $\sim 100 \mathrm{~km}$ [Yuan et al., 2001]. The minimum global average determined from Bouguer gravity is $\sim 50-60 \mathrm{~km}$, with the southern highlands being $\sim 10-20 \mathrm{~km}$ thicker than the northern lowlands, based on maintaining a non-negative crustal thickness beneath the Isidus impact basin [Zuber et al., 2000; Wieczorek and Zuber, 2004]. The maximum crustal thickness is $\sim 100-115 \mathrm{~km}$ based on viscous relaxation of the Hellas basin and the dichotomy boundary [Nimmo and Stevenson, 2001; Zuber et al., 2000]. Since the focus in this study is deriving values of $T_{e}$, the crustal thickness is held constant at a value of $100 \mathrm{~km}$. Running best-fit calculations for $t_{c r}=50-110 \mathrm{~km}$ in $10 \mathrm{~km}$ increments, we found $100 \mathrm{~km}$ marginally provided the best fit and the best agreement between the resulting modeled topographies and the observed topography for the best-fit LOS acceleration profiles (Figure 6).

[20] The results are summarized in Table 2 with plots of the resulting best-fit model acceleration profiles and the spacecraft accelerations in Figure 7. The sensitivity of the solution to variations in the parameters is evaluated by analyzing the trade-off between the parameters. Contours of misfit are displayed on two-parameter projections to identify regions of favorable solutions where the acceptable misfit is taken to be less than the residual standard error (Figure 8). All of the profiles analyzed yield similar parameter solutions with $T_{e} \sim 19-23 \mathrm{~km}, \rho_{s} \sim 3030$ $3080 \mathrm{~kg} \mathrm{~m}^{-3}$, and a disk thickness $\sim 16.5-17.5 \mathrm{~km}$.

\subsection{Discussion}

\subsubsection{Effective Elastic Thickness}

[21] The $T_{e}$ values obtained by the model reflects the elastic strength of the lithosphere at the time Thaumasia was emplaced since the flexural wavelength, determined by $T_{e}$ at the time of loading, does not change unless subsequent stresses on the lithosphere impart a new flexural signal. In general, $T_{e}$ increases as the planet cools, and younger features will therefore reflect a larger value of $T_{e}$ and obscure previous flexural signals. The values determined in our model are consistent with a Noachian formation age for the Thaumasia Highlands. For example, Zuber et al. [2000] and McGovern et al. [2004], obtained values of $T_{e}<$ $20 \mathrm{~km}$ for all Noachian features they studied and McKenzie et al. [2002] obtained $T_{e}=15 \mathrm{~km}$ for the bulk of the southern highlands which for the most part have Noachian surface ages. This is in agreement with the interpretation of the flexural moat being filled with Late-Noachian and Hesperian materials and places the formation of Thaumasia in the earliest epoch of Mars encompassing the first $\sim 500$ Ma after planetary accretion [Hartmann and Neukum, 2001].

[22] The modeled flexure of a thin-elastic shell provides an explanation for the general topographic configuration of the Thaumasia Highlands; that of an arcuate mountain belt circumscribing a depressed interior plateau, and a flexural moat which is inferred from the surface geology and gravity. For Thaumasia, with a diameter $\sim 2700 \mathrm{~km}$, most of the power in its topography will be at low harmonic degrees that generally are in an isostatic regime (i.e., no bending stresses). Most of the power in the topography of the disk load is in harmonic degrees $0-10$. The edge of the disk contains shorter wavelength spectral power and therefore exhibits a larger degree of elastic support explaining the topographic high of the Thaumasia Highlands at the edge of the Thaumasia Plateau.

\subsubsection{Crust Density and Initial Disk Elevation}

[23] The best-fit disk thicknesses obtained in the models of $16-22 \mathrm{~km}$ result in $\sim 4-5 \mathrm{~km}$ of surface relief at the disk margins for the corresponding best-fit $T_{e}$ and $\rho_{s}$ values, comparable to the magnitude of relief of the Thaumasia Highlands (e.g., Figure 6). This leads to crustal roots $\sim 11.5-13.5 \mathrm{~km}$ thick. Using Bouguer gravity and MOLA topography, Neumann et al. [2004] find crustal thickening 


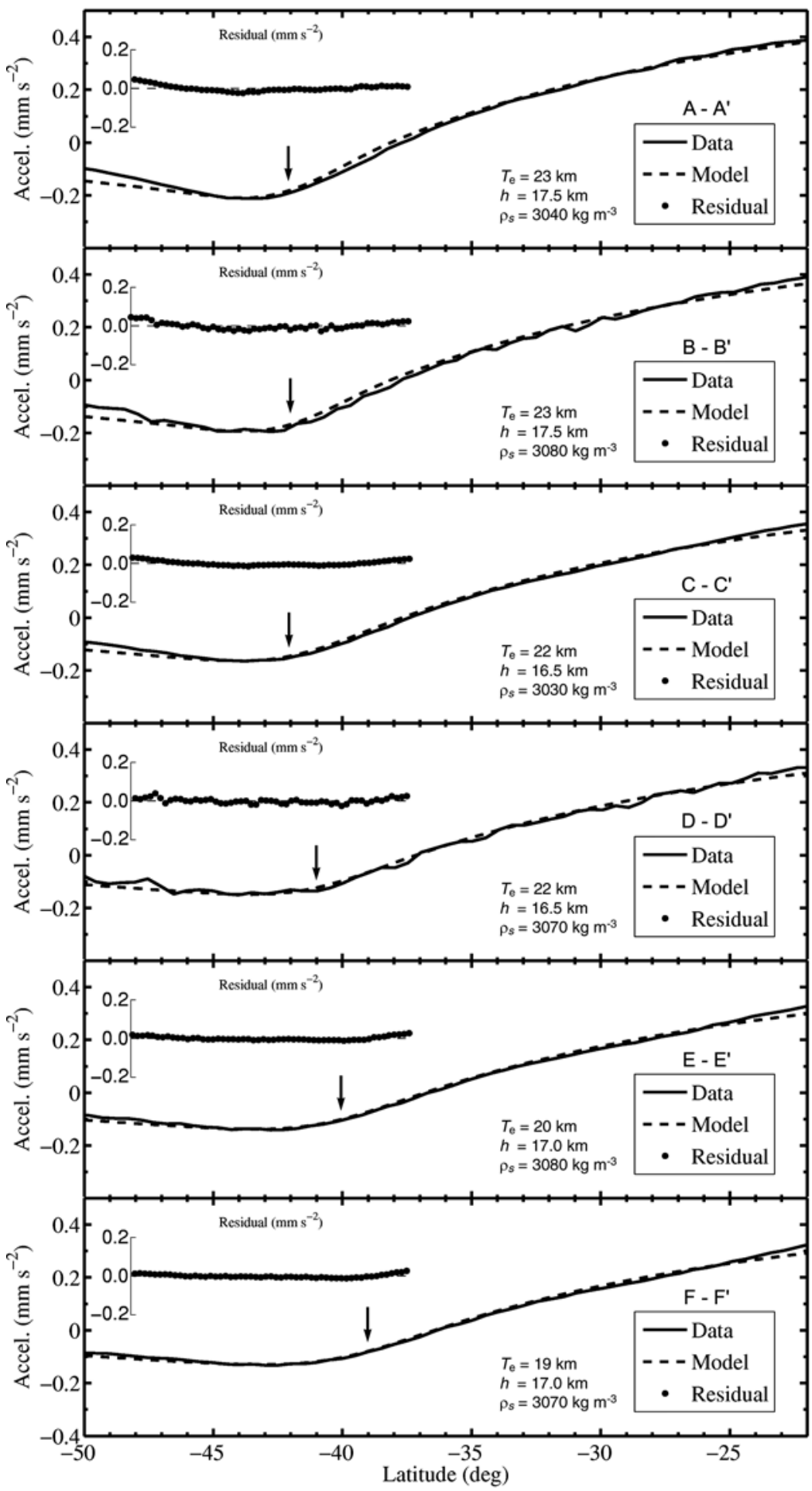

Figure 7. The six LOS acceleration profiles from MGS with best-fit modeled LOS acceleration profiles and the residual (inset). Arrows denote disk edge.

beneath the Thaumasia Highlands on the order of $10-$ $15 \mathrm{~km}$, assuming an isostatic, uniformly dense crust $\left(\rho_{s}=\right.$ $2900 \mathrm{~kg} \mathrm{~m}^{-3}$ ).

[24] The nominal range of surface densities found in this study, $3030-3080 \mathrm{~kg} \mathrm{~m}^{-3}$ for the six profiles, are lower than the densities of the Martian meteorites, typically 3200 to $3300 \mathrm{~kg} \mathrm{~m}^{-3}$ [Lodders, 1998], and values obtained for the Tharsis volcanoes, typically $\sim 3200 \mathrm{~km} \mathrm{~m}^{-3}$ [McKenzie et al., 2002; Turcotte et al., 2002; McGovern et al., 2004; Belleguic et al., 2005]. This may be attributable to the Thaumasia Highlands' significantly older age. Surface densities obtained from analysis of localized admittance for other portions of Noachian age crust are lower [Nimmo and Tanaka, 2005], possibly due to high porosity (resulting from 

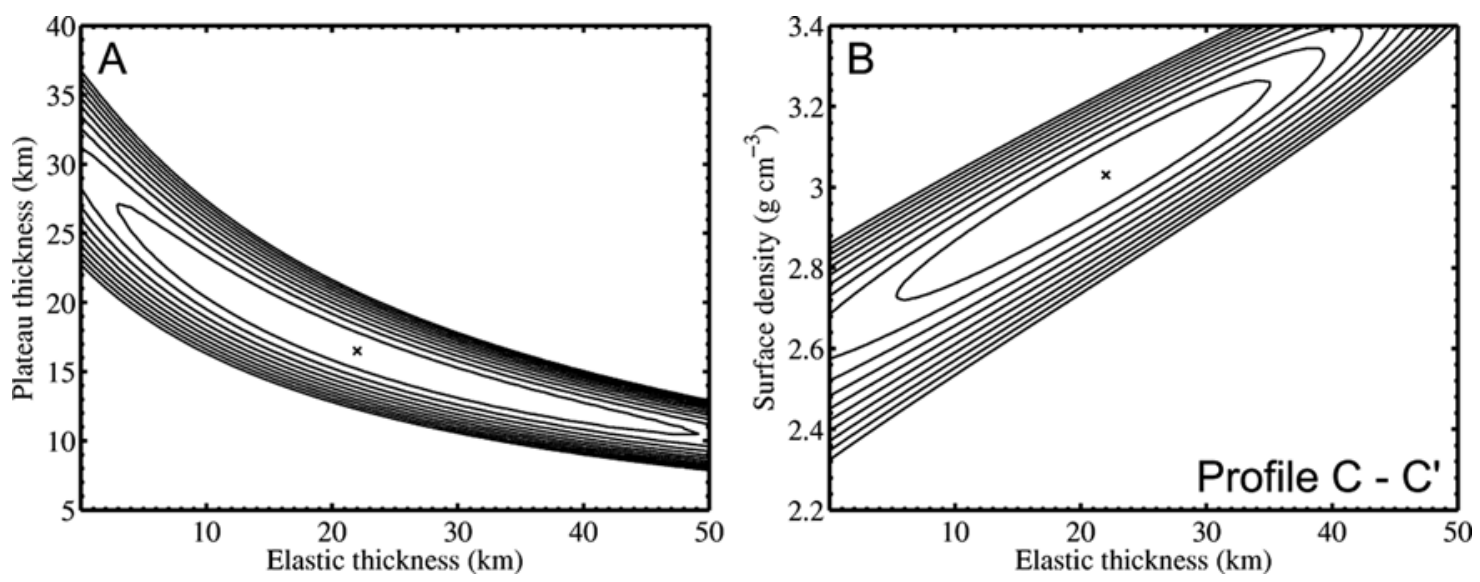

Figure 8. Contours of misfit, defined as the residual sum of squares, displayed on two-parameter projections for a representative profile $\left(\mathrm{C}-\mathrm{C}^{\prime}\right)$. Contour intervals represent multiples of the residual standard error with minimum misfit denoted by " $\times$ ".

impacts), presence of lower density sediments, or possibly a near surface ice component. Three regions of the southern highlands investigated by McGovern et al. [2004] were found to have surface densities in the range of 2500 to $3000 \mathrm{~kg} \mathrm{~m}^{-3}$. Nimmo [2002] obtained a crust density of $2500 \mathrm{~kg} \mathrm{~m}^{-3}$ for a region of the highlands straddling the dichotomy boundary.

[25] Within the Tharsis region, McKenzie et al. [2002] obtained a density of $2350 \mathrm{~kg} \mathrm{~m}^{-3}$ for a study region centered on Valles Marineris that included the northern half of the Thaumasia Plateau. Setting the disk density in our model to that obtained by McKenzie et al. [2002] results in a significantly larger topographic signal, as the lower density results in an increase in disk thickness to match the gravity, and the increase in the density contrast between the disk and mantle increases the buoyant support. This low-density model produces topography more than $\sim 5 \mathrm{~km}$ in excess of that observed for the Thaumasia Highlands. As our bestfit model solutions yield topographic relief of similar magnitude to that of the Thaumasia Highlands we conclude that the low surface density obtained by McKenzie et al. [2002] does not extend into the Thaumasia Highlands and may reflect low surface densities around Valles Marineris. McGovern et al. [2004] obtained density ranges of 2100$2900 \mathrm{~kg} \mathrm{~m}^{-3}$ for three chasma of Valles Marineris, with varying degrees of subsurface loading with lowest density values obtained with top-loading only models. For Solis Planum, the portion of the Thaumasia Plateau south of Valles Marineris, and encompassing the northern portion of the acceleration profiles used in this study, McGovern et al. [2004] obtained a crust density of $2900 \mathrm{~kg} \mathrm{~m}^{-3}$ implying the low surface densities observed in these other studies are confined northward of the region studied here. Further, when considering the range of models that fall within the acceptable misfit (Table 2), the minimum and maximum permissible densities are $2710-3320 \mathrm{~kg} \mathrm{~m}^{-3}$ respectively. The density obtained for Solis Planum by McGovern et al. [2004] falls well within this range, however, the low densities obtained northward around Valles Marineris generally do not [McKenzie et al., 2002; McGovern et al., 2004] and indicate the density of the southern margin of Thaumasia is distinct.

\subsection{Summary}

[26] We find that a model depicting the gravitational relaxation of a plateau can successfully fit the LOS acceleration data of MGS over the Thaumasia Highlands and explain the topographic configuration of the arcuate mountain belt, depressed interior plateau, and flexural moat inferred from the surface geology and gravity. Minimizing the misfit between six modeled profiles and the LOS acceleration profiles has provided reasonable estimates of the effective elastic thickness, crust density, and amount of crustal thickening (i.e., disk thickness) for the Thaumasia Highlands. The results are similar for all profiles with $T_{\mathrm{e}} \sim$ $20 \mathrm{~km}, \rho_{\mathrm{s}} \sim 3000 \mathrm{~kg} \mathrm{~m}^{-3}$ and $h \sim 17 \mathrm{~km}$. In general, $T_{\mathrm{e}}$ increases as the planet cools and the value obtained reflects $T_{\mathrm{e}}$ and the time of lithospheric loading, and thus provides information on the formation age. Zuber et al. [2000] and McGovern et al. [2004], obtained values of $T_{\mathrm{e}}<20 \mathrm{~km}$ for all Noachian features they studied and McKenzie et al. [2002] obtained $T_{\mathrm{e}}=15 \mathrm{~km}$ for the bulk of the southern

Table 2. LOS Model Results ${ }^{\mathrm{a}}$

\begin{tabular}{|c|c|c|c|c|c|}
\hline Profile & $T_{\mathrm{e}}(\mathrm{km})$ & $h(\mathrm{~km})$ & $\rho_{s}\left(\mathrm{~g} \mathrm{~cm}^{-3}\right)$ & $\operatorname{RSS}\left(\mathrm{mm} \mathrm{s}^{-2}\right)$ & $R^{2}$ Statistics \\
\hline$A-A^{\prime}$ & $23_{(3-45)}$ & $17.5_{(12.0-30.0)}$ & $3.04_{(2.71-3.26)}$ & $1.27 \times 10^{-2}$ & 0.99455 \\
\hline${\mathrm{B}-\mathrm{B}^{\prime}}^{\prime}$ & $23(3-49)$ & $17.5_{(11.0-31.5)}$ & $3.08_{(2.75-3.32)}$ & $1.79 \times 10^{-2}$ & 0.99171 \\
\hline $\mathrm{C}-\mathrm{C}^{\prime}$ & $22_{(3-49)}$ & $16.5_{(10.5-27.0)}$ & $3.03_{(2.72-3.26)}$ & $0.82 \times 10^{-2}$ & 0.99528 \\
\hline D-D ${ }^{\prime}$ & $22(3-51)$ & $16.5_{(10.0-29.0)}$ & $3.07_{(2.75-3.31)}^{(2.20)}$ & $0.90 \times 10^{-2}$ & 0.99378 \\
\hline$E-E^{\prime}$ & $20(3-46)$ & $17.0_{(10.5-27.5)}$ & $3.08(2.82-3.28)$ & $0.53 \times 10^{-2}$ & 0.99613 \\
\hline F-F ${ }^{\prime}$ & $19(4-45)$ & 17.0 & $3.07(2.83-3.287$ & $0.40 \times 10^{-2}$ & 0.99676 \\
\hline
\end{tabular}

${ }^{\text {a }}$ Range of parameter values in parenthesis given for a misfit range within the standard deviation of the misfit. Crust thickness is held constant (100 km) for all models and crust density set equal to load density. 


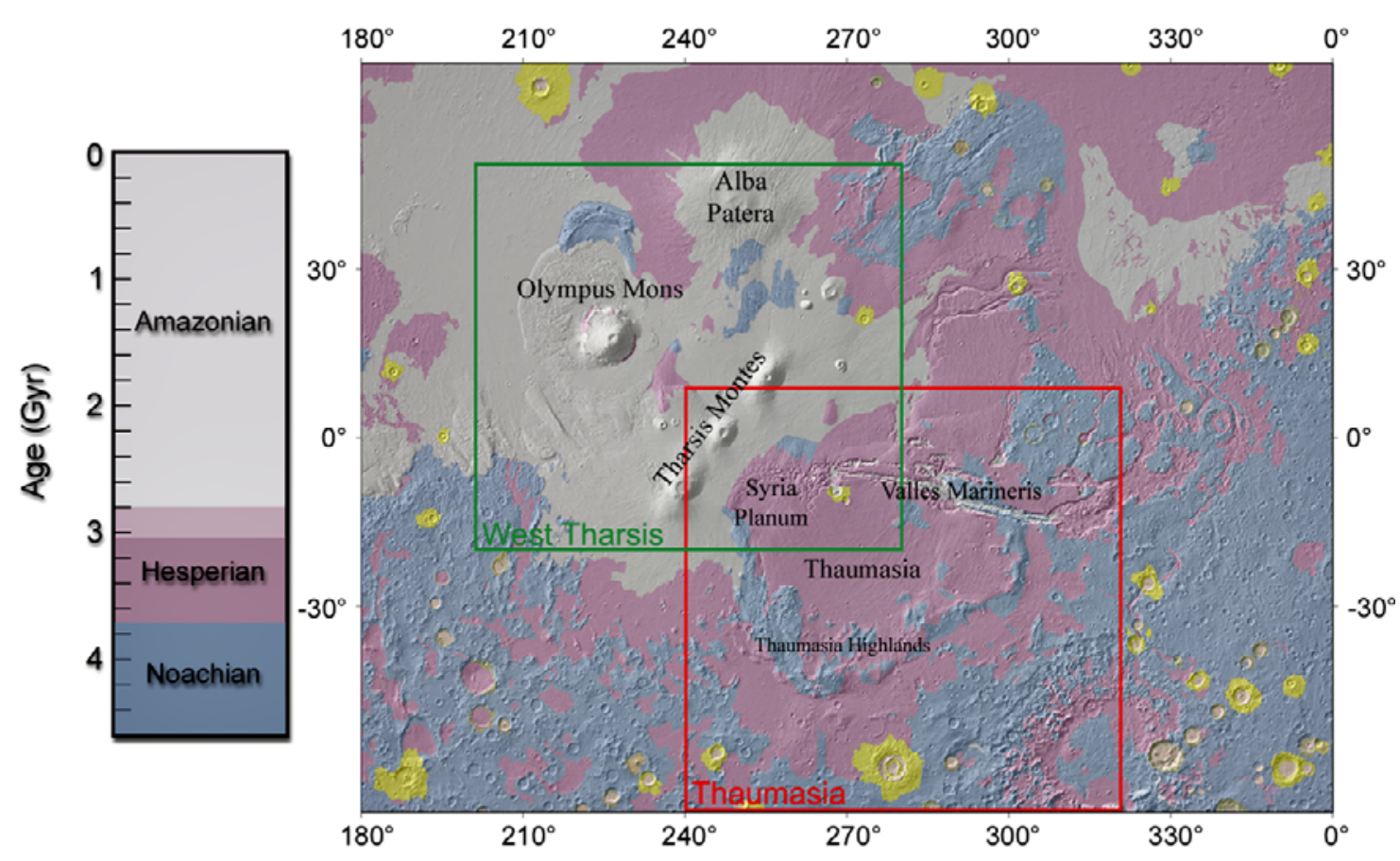

Figure 9. The geologic timescale of Mars divided into three stratigraphic epochs: Noachian, Hesperian, and Amazonian, with an estimated absolute timescale [Hartmann and Neukum, 2001] and a simplified geologic map (adapted from the study of Scott and Tanaka [1986]) depicting the surface ages corresponding to the three stratigraphic epochs. Units colored yellow, olive, and beige are impact crater material of unspecified age. Colored boxes outline regions where admittance was determined in this study.

highlands which for the most part have Noachian surface ages. This is consistent with the interpretation of the flexural moat being filled with Late-Noachian and Hesperian materials and places the formation of Thaumasia in the earliest epoch of Mars encompassing the first $\sim 500 \mathrm{Ma}$ after planetary accretion.

\section{The Admittance of Tharsis}

\subsection{Background}

[27] The Tharsis rise was largely in place by the end of the Noachian Epoch [Phillips et al., 2001] and its formation contributes significantly to the global shape [Smith et al., 1999a] and long wavelength gravity field of Mars [Smith et al., 1999b]. A majority of the tectonic and volcanic activity of Tharsis peaked early and decreased with time [Scott and Tanaka, 1986; Anderson et al., 2001] although more limited volcanism appears to have persisted later in the planet's history. With volcanic flows as young as $10-200 \mathrm{Ma}$ [Hartmann, 1999, 2005; Neukum et al., 2004] Tharsis can still be considered a volcanically active region.

[28] In a general sense, the southeastern half of the rise differs markedly from the western half of the rise (Figure 9). The western half of the rise, subsequently referred to here as west Tharsis, is characterized by large shield volcanism with high central edifices, calderas, and flanking rift zones with surface units of Hesperian and Amazonian age predominating. Conversely, the southeastern half, referred to as Thaumasia, encompassing the Thaumasia Highlands, Valles Marineris, and Solis, Sinai, and Syria Plana, is characterized by widespread, diffuse volcanic construction, an absence of large shield structures and calderas, with surface units of Noachian and Hesperian age predominating. This general trend observed in surface ages, Noachian-dominated units in the southern margin of Thaumasia progressing in age across the rise to Amazonian-dominated surface units in west Tharsis, suggests there has been an alteration to the underlying convection since the Early Noachian resulting in a migration in volcanic activity away from Thaumasia and the preservation of Noachian terrains on the plateau margin. Further, the style of volcanic construction, changing from plateau building in the Noachian to the formation of large shields in the Amazonian, perhaps reflects the changing response of the lithosphere to volcanic loads.

[29] If the heat flux from the interior of the planet has been spatially uniform across Tharsis for the duration of Martian history, a geophysical manifestation of this trend in surface ages would be anticipated in the effective elastic thickness values, $T_{e}$. This is because $T_{e}$ values generally increase for younger surface features as a result of the thickening of the rigid outer portion of the planet over time. The admittance, the function relating gravity to topography, can be used to estimate $T_{e}$ on a regional basis [e.g., McKenzie, 1994; Simons et al., 2000; Watts, 2001; McGovern et al., 2002; Belleguic et al., 2005; Wieczorek and Simons, 2005]. We derive values of the admittance from LOS acceleration profiles of MGS for the two halves of Tharsis. We fit the observed admittance with modeled admittances. In addition to estimating $T_{e}$, the surface density $\rho_{s}$ is fit to identify variations between the study regions. It is also assumed that loading at the Moho can produce surface topography and the ratio of bottom to top loading, $F=F_{2} /$ 

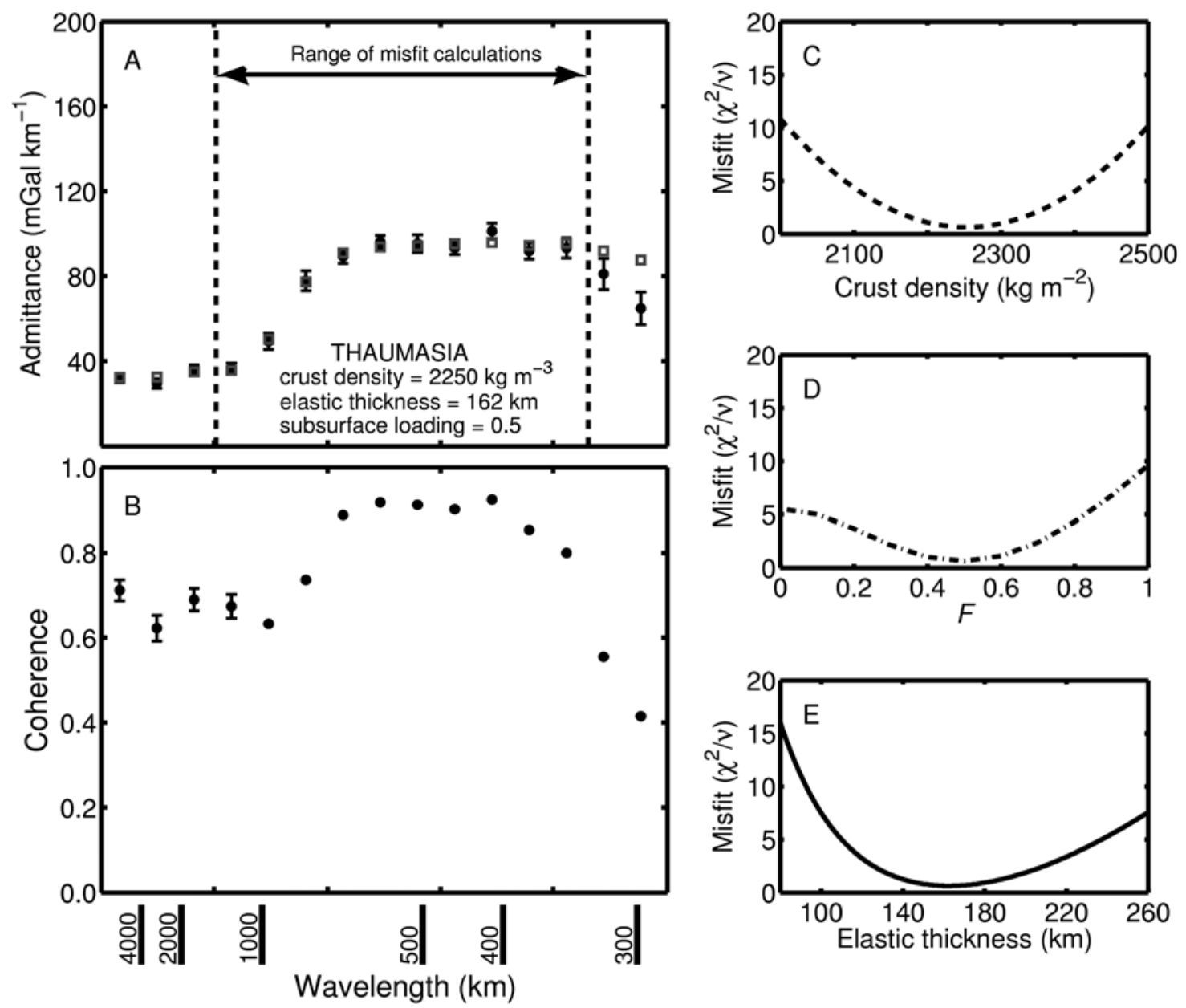

Figure 10. Results for Thaumasia $\left(240^{\circ}\right.$ to $320^{\circ} \mathrm{E},-60^{\circ}$ to $5^{\circ} \mathrm{N}$ ). (A) Observed admittance (black circles) from LOS data (1D) and best-fit admittance derived from modeled LOS spacecraft acceleration profiles (gray squares). (B) Observed coherence as a function of wavelength. (C) Misfit profiles for crust density. (D) Misfit profiles for loading ratio. (E) Misfit profiles for elastic thickness.

$F_{1}$, is also fit as a parameter where $F_{1}$ and $F_{2}$ are the fractions of loading at the surface and Moho respectively [e.g., McKenzie, 2003].

\subsection{Admittance Model}

[30] The details of the LOS admittance method that we employ in this study can be found in the study of McKenzie and Nimmo [1997] and McKenzie et al. [2002], however these models did not consider subsurface loading. Other studies [e.g., Zuber et al., 2000; McGovern et al., 2002; Belleguic et al., 2005] have utilized harmonic coefficients of surface gravity models to derive admittances. The tracking data provides a direct measurement of the gravity signal at a location, rather than the harmonic field derived from a model that produces a global fit. However, using the LOS acceleration requires a larger area to derive an accurate admittance making it more difficult to isolate geologic provinces [Pérez-Gussinyé et al., 2004; Crosby, 2007].

[31] In the frequency domain we used the mean value of the observed admittance, $Z_{\circ}^{f}(k)$, with standard deviation, $\Delta Z_{\circ}^{f}(k)$, obtained from the gravity and topography in a number of wave number bands using the multitaper method [Thomsen, 1982; McKenzie and Fairhead, 1997] with three tapers in each direction. The best-fit theoretical admittance curve is determine by minimizing the chi-square function [e.g., Press et al., 1992]

$$
\chi^{2}=\sum_{i=1}^{N}\left[\left(Z_{\circ}^{f}-Z_{c}^{f}\right) / \Delta Z_{\circ}^{f}\right]^{2}
$$

where $N$ is the number of wave bands used and $Z_{c}^{f}(k)$ is a model admittance obtained by using the multitaper method on a synthetic LOS acceleration data set. These synthetic LOS accelerations are calculated from the observed topography and an admittance $Z$ which is calculated using:

$$
Z=4 \pi G \rho_{s}\left(\frac{l+1}{2 l+1}\right)\left[1-\left(1-\frac{t_{c r}}{R}\right)^{l+2} A\right]
$$

where $A$, adapted here for a thin spherical shell from McKenzie and Fairhead [1997], is

$$
A=\frac{\alpha_{b} F^{2} \rho_{s}^{2}+\alpha_{t} \Delta \rho^{2}}{F^{2} \rho_{s}^{2}+\alpha_{t}^{2} \Delta \rho^{2}}
$$


Table 3. Best-Fit Models Using Windowed Synthetic LOS Accelerations $^{\text {a }}$

\begin{tabular}{llll}
\hline Parameter & \multicolumn{1}{c}{ Unit } & \multicolumn{1}{c}{ Thaumasia } & West Tharsis \\
\hline$\lambda$ & $\mathrm{km}$ & $330-1400$ & $390-1400$ \\
$T_{\mathrm{e}}$ & $\mathrm{km}$ & $162_{(118-202)}$ & $81_{(75-88)}$ \\
$\rho_{s}$ & $\mathrm{~kg} \mathrm{~m}^{-3}$ & $2250_{(2210-2310)}$ & $3150_{(3110-3180)}$ \\
$t_{c}$ & $\mathrm{~km}$ & 100 & 100 \\
$F$ & & $0.5(0.3-0.6)$ & $0.1_{(0.1-0.1)}$ \\
$\left(\chi^{2} / \nu\right)_{\text {min }}$ & & 0.63 & 0.74 \\
$Q_{\text {min }}$ & & 0.73 & 0.59 \\
\hline
\end{tabular}
$\chi_{\min }^{2}$.

${ }^{\mathrm{a}}$ The values in parentheses give ranges of solutions for which $\chi^{2} / \nu<1.5$

and $\alpha_{t}$ and $\alpha_{b}$ represent the inverse of the degree of compensation for a given degree harmonic for surface and subsurface (or "bottom") loading respectively [see Turcotte et al., 1981] for a derivation and discussion of the degree of compensation for a thin elastic shell). $F$ is the fraction of subsurface loading and is assumed to be statistically independent from surface loading [Forsyth, 1985]. If correlation between surface and subsurface loading is very high over a wide region, then density estimates will differ from the average density of the topography and the rigidity will be underestimated [McKenzie and Fairhead, 1997].

[32] Synthetic LOS profiles are generated from the observed topography and processed to yield model admittance values in an identical manner to the observed LOS profiles [McKenzie et al., 2002]. Although time-consuming, doing so avoids the problem of comparing the observed (windowed) admittance with an unwindowed theoretical curve which result in $T_{\mathrm{e}}$ estimates that are biased toward lower values [Pérez-Gussinyé et al., 2004; Crosby, 2007]. Spectral leakage can result in overestimated admittances at the longest wavelengths. We therefore neglect admittance values for wavelengths $>1400 \mathrm{~km}$ in the calculations of the misfit between observed and predicted admittance. The best fit was determined by varying the parameters $T_{e}, \rho_{s}$, and $F$ in increments of $1 \mathrm{~km}, 10 \mathrm{~kg} \mathrm{~m}^{-3}$, and 0.1 . The goodnessof-fit for the models are evaluated using the incomplete gamma function $Q$ [Press et al., 1992], where very small values of $Q(\ll 1)$ imply the misfit between the data and the theoretical curve is unlikely to be due to chance fluctuations and the model should be rejected. For values of $Q \sim 0.5$, the variance in the data is approximated well by the variance in the fit and the reduced chi-square value, $\chi^{2} / \nu$ (where $\nu$ is the degrees of freedom), is $\sim 1$.

[33] As discussed in section 2.4, there is generally a tradeoff between the elastic thickness and the crustal thickness. The constraint on the crustal thickness is relatively weak as this parameter affects the theoretical admittance at longer wavelengths where flexural effects can be masked by a convective signature [Barnett et al., 2000] and spectral leakage [Pérez-Gussinyé et al., 2004]. Since the focus in this study is deriving values of $T_{e}$, the crustal thickness is again held constant at $100 \mathrm{~km}$.

\subsection{Admittance Results}

\subsubsection{Thaumasia}

[34] A study area of $240^{\circ}$ to $320^{\circ} \mathrm{E}$ longitude and $-60^{\circ}$ to $5^{\circ} \mathrm{N}$ latitude was selected encompassing Thaumasia (Figure 9). The resulting best-fit model parameters are listed in Table 3 and the observed admittance and the nominal best-fit modeled admittance are shown in Figure 10. As can be seen, at sufficiently short wavelengths $(<800 \mathrm{~km}), Z$ is approximately constant as the lithosphere is not deformed by the topography. The admittance at these wavelengths is determined exclusively by the density of the corresponding components of surface topography, $Z=2 \pi \rho_{\mathrm{s}} G$. The best-fit value is $2250 \mathrm{~kg} \mathrm{~m}^{-3}$, a value predominately lower than values derived in admittance studies of other regions of Mars [e.g., McKenzie et al., 2002; McGovern et al., 2002; Zuber et al., 2000]. The best-fit density is also smaller than that of the SNC meteorites [Lodders, 1998], which are generally accepted to be samples of the Martian crust [Longhi et al., 1992; McSween, 1994]. It is however, consistent with values derived by other studies within the Thaumasia region. McKenzie et al. [2002], considering top loading only, derived $\rho_{s}=2350 \mathrm{~kg} \mathrm{~m}^{-3}$ for a region encompassing the northern half of Thaumasia centered on Valles Marineris at longitudes 260 to $350^{\circ} \mathrm{E}$ and latitudes -35 to $25^{\circ} \mathrm{N}$. McGovern et al. [2004] derived $\rho_{s}=2200$, 2300, and $2500 \mathrm{~kg} \mathrm{~m}^{-3}$ for Candor, Hebes, and Capri Chasma of Valles Marineris respectively when only considering top loading. In section 2, we found that the low density does not include the Thaumasia Highlands and is likely confined northward toward Valles Marineris. The low density may be the result of subsurface ground ice or a lowdensity sedimentary component of the crust. Valles Marineris has been the source region of large outflow channels in the past [e.g., Lucchitta et al., 1992]. However, if the ground ice is of sufficient abundance to lower the surface density to $2250 \mathrm{~kg} \mathrm{~m}^{-3}$, it must be at a depth greater than $\sim 1 \mathrm{~m}$ because the Mars Odyssey Gamma Ray Spectrometer does not see elevated hydrogen in the region [Feldman et al., 2002; Boynton et al., 2002]. Light-toned, layered rocks, interpreted to be sedimentary, are observed in thick sequences within the Valles Marineris canyon system [Malin and Edgett, 2000, 2001] along with light-toned units possibly of similar lithology upon the surrounding plateau [Edgett,

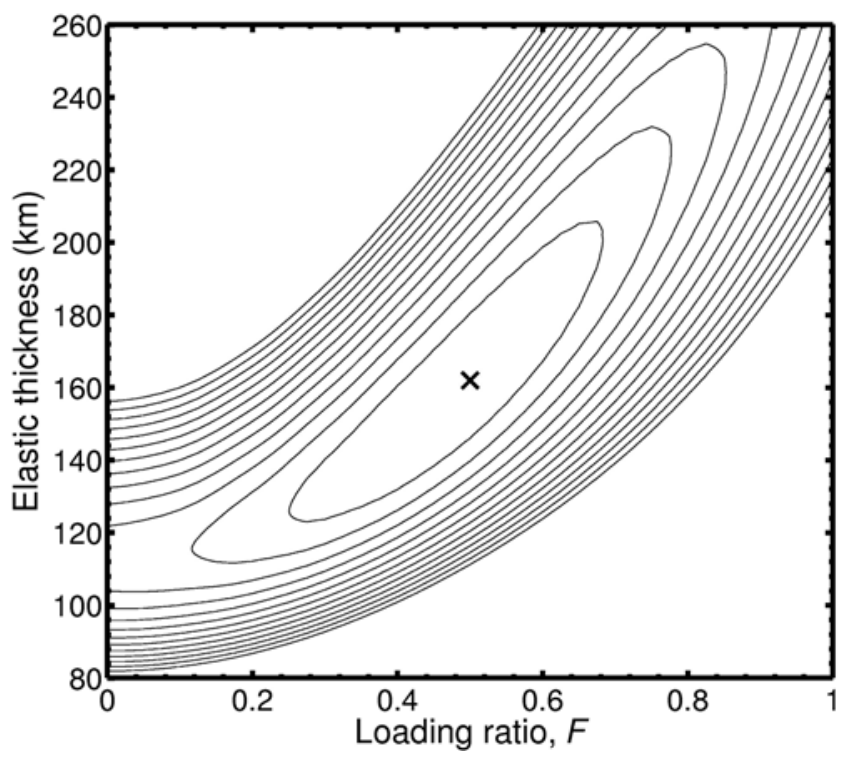

Figure 11. Misfit contours for $T_{\mathrm{e}}$ versus $F$. The " $\times$ " denotes the minimum misfit point and contour intervals are $0.5 \chi_{\min }^{2}$. As can be seen, if top loading is assumed $(F=0)$, $T_{e}$ is underestimated. 

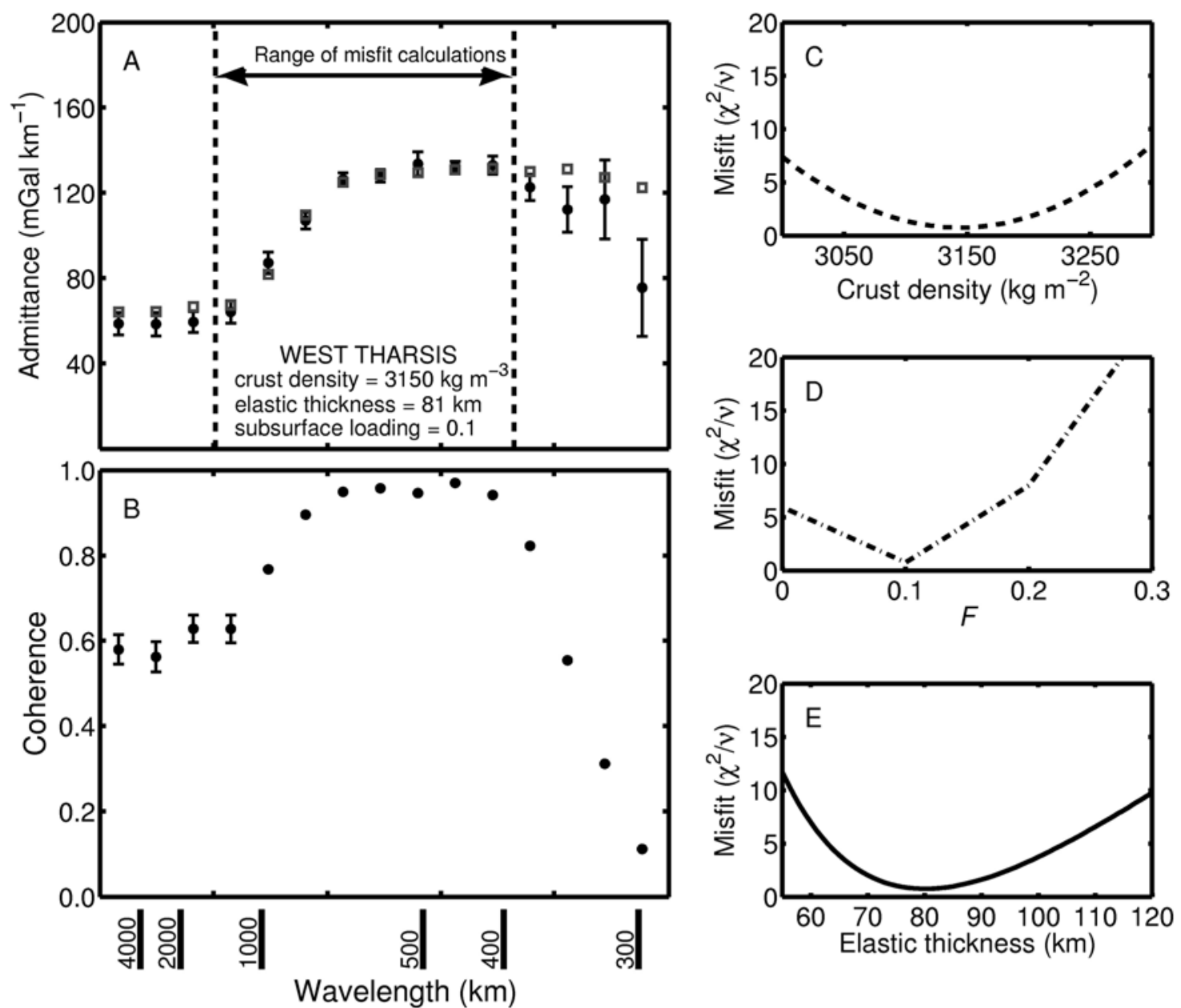

Figure 12. Results for west Tharsis $\left(200^{\circ}\right.$ to $280^{\circ} \mathrm{E},-20^{\circ}$ to $\left.45^{\circ} \mathrm{N}\right)$. (A) Observed admittance (black circles) from LOS data (1D) and best-fit admittance derived from modeled LOS spacecraft acceleration profiles (gray squares). (B) Observed coherence as a function of wavelength. (C) Misfit profiles for crust density. (D) Misfit profiles for loading ratio. (E) Misfit profiles for elastic thickness.

2005]. This observation could explain the low densities found in the region if significant portions of the crust are composed of lower density sediments or include a significant ice component. Sediment and ice deposits in the region are predicted by Dohm et al. [2001] who interpret much of Tharsis having been a Europe-size basin during the Noachian which would have formed a catchment for water and sediments. The wall rocks exposed by the large chasma, which represent the $>10 \mathrm{~km}$ sequence of rocks that comprise the Thaumasia Plateau have been interpreted to be igneous in origin, likely the result of volcanic flood lavas [McEwen et al., 1999] and igneous intrusion [Williams et al., 2003]. The low densities found for this region in this study and in other studies [McKenzie et al., 2002; McGovern et al., 2002, 2004] argue that a low-density component is present in at least the top few kilometers of the crust. The vertical relief of topography is generally of the order of several kilometers and therefore the crust density value obtained by admittance studies pertains to only the upper few kilometers of the crust.

[35] Since the surface density is determined by the short wavelength admittance, it is well constrained and is observed to be relatively invariant relative to changes in the other parameters. There is however, a general trade-off between $T_{e}$ and $F$. If $F$ is held fixed at 0.0 , i.e., top loading only, a smaller value of $T_{e}$ is obtained, $T_{e}=112 \mathrm{~km}$, versus $T_{e}=162 \mathrm{~km}$ and $F=0.5$ when $F$ was allowed to vary. As can be seen, if bottom loading is present but not accounted for, $T_{e}$ is underestimated (Figure 11).

[36] The best-fit value of elastic thickness of $162 \mathrm{~km}$ is larger than the values estimated using the LOS acceleration profiles transecting the Thaumasia Highlands $(<50 \mathrm{~km})$. The likely reason for this is that the Thaumasia region as a whole contains features that are of varying geologic ages with many features being younger than the Thaumasia Highlands. For example, Valles Marineris and Noctis Labyrinthes are Hesperian in age, Syria Planum has experienced multiple episodes of volcanic and tectonic activity, and areally extensive Hesperian flood basalts cap the interior of the plateau. In addition, Thaumasia may have experienced continued thermal subsidence of the plateau after the initial flexural signal of the Thaumasia Highlands was established. Regional spectral estimates of $T_{e}$ will be weighted by features with the largest amplitude [Forsyth, 1985] and these younger features, many with significant relief such as Valles Marineris $(\sim 8 \mathrm{~km})$, dominate the admittance and 


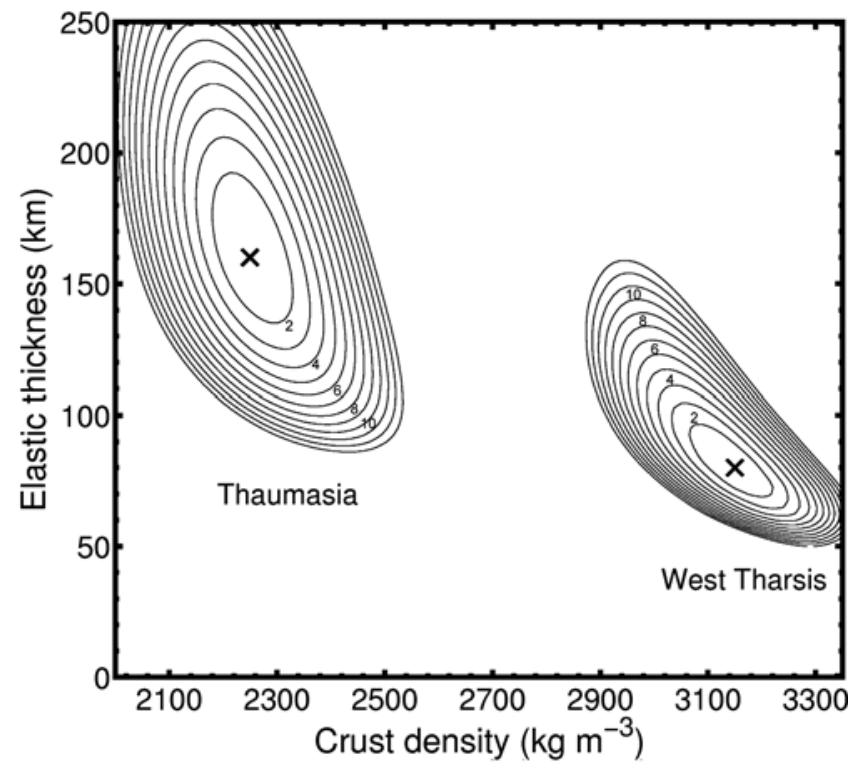

Figure 13. Misfit contours for $T_{e}$ and $\rho_{s}$ for the Thaumasia (left) and west Tharsis (right) nominal models. The " $x$ " marks the minimum misfit points, and contour intervals are $2 \chi_{\min }^{2}$.

reflect a larger $T_{e}$. McGovern et al. [2004] derive large values of $T_{e}$ in three chasma of Valles Marineris with values generally exceeding $100 \mathrm{~km}$. However, for Solis Planum, the southern portion of the Thaumasia Plateau, they derive $T_{e}=24-37 \mathrm{~km}$, a range of values reflecting the older age of the southern margin of the plateau and more consistent with the values we derived in section 2 .

\subsubsection{West Tharsis}

[37] A region of the western portion of Tharsis, $200^{\circ}$ to $280^{\circ} \mathrm{E}$ longitude and $-20^{\circ}$ to $45^{\circ} \mathrm{N}$ latitude (Figure 9), was selected to incorporate the largely Amazonian surface ages that are observed there [Scott and Tanaka, 1986]. This study region includes the large shield volcanoes that dominate the western half of Tharsis and include: Arsia, Pavonis, and Ascraeus Mons (collectively referred to as the Tharsis Montes), Olympus Mons, and other smaller volcanic edifices.

[38] The admittance for this region (Figure 12) is best fit with a surface density, $3150 \mathrm{~kg} \mathrm{~m}^{-3}$, and an elastic thickness, $81 \mathrm{~km}$ for $t_{c r}=100 \mathrm{~km}$ with little to no bottom loading, $F=0.1$ (Table 3 ). This value for $T_{e}$ is at odds with the Amazonian surface ages when compared with the larger $T_{e}$ value obtained for Thaumasia where predominantly Noachian and Hesperian surface ages persist. Selecting a misfit criterion of 1.5 times the minimum misfit to determine a reasonable fit gives $118-202 \mathrm{~km}$ and $75-88 \mathrm{~km}$ for the elastic thicknesses of Thaumasia and west Tharsis respectively, and $2210-2310 \mathrm{~kg} \mathrm{~m}^{-3}$ and $3110-3180 \mathrm{~kg}$ $\mathrm{m}^{-3}$ for the surface densities of Thaumasia and west Tharsis respectively. Contour plots of misfit for the two regions show that $\rho_{s}$ is tightly constrained for both regions (i.e., the acceptable range in $\rho_{s}$ is relatively small). Further, the difference in densities is more robust than the difference between $T_{e}$ where the contours largely overlap (Figure 13). If $T_{e}$ is held constant at a mean value of $122 \mathrm{~km}$ for both regions, best-fit densities of 3010 and $2320 \mathrm{~kg} \mathrm{~m}^{-3}$ are obtained for west Tharsis and Thaumasia respectively
(Figure 14A) with an increase in minimum misfit to 4.329 and 2.158 respectively. If the surface densities for both regions are held constant at a mean density of $2700 \mathrm{~kg} \mathrm{~m}^{-3}$ (Figure 14B), west Tharsis yields a larger best-fit $T_{e}$, $172 \mathrm{~km}$, than that of Thaumasia, $100 \mathrm{~km}$. The model misfits however, become quite large, 26.08 and 19.43 for west Tharsis and Thaumasia respectively. From this, we see that the evidence for a systematic difference in $T_{e}$ between the two areas is weak, but the evidence that the surface densities are different is quite strong. This is further supported by the fact that both of the admittance curves roll-off at similar wavelengths, $\sim 800 \mathrm{~km}$.

[39] The difference in surface densities is not surprising. Thaumasia has experienced fewer volcanic resurfacing events during its history. Many of the terrains are Noachian in age and were likely extensively brecciated from heavy bombardment and/or may have been heavily sedimented from an earlier, wetter, warmer climate. On the other hand, crater counts indicate relatively young model surface ages for the western half of Tharsis. For example, Hartmann [2005] find an average surface model age for Arsia Mons, the southern most Tharsis Montes volcano, of $\sim 200$ to 1000 Ma. Neukum et al. [2004] estimate a surface age of $\sim 100 \mathrm{Ma}$ for the large central caldera of Ascraeus Mons, the northern most Tharsis Montes volcano. Other studies also obtain higher surface densities for the Tharsis volcanoes $\left(3100 \pm 200 \mathrm{~kg} \mathrm{~m}^{-3}\right)$, than are found for various regions that are composed of Noachian crust $\left(2500-3000 \mathrm{~kg} \mathrm{~m}^{-3}\right)$ [McKenzie et al., 2002; Turcotte et al., 2002; Nimmo, 2002; McGovern et al., 2004; Belleguic et al., 2005]. Further, the SNC meteorites, with all but one having crystallization ages $<1.3 \mathrm{Ga}$, have whole rock densities typically 3200 to $3300 \mathrm{~kg} \mathrm{~m}^{-3}$ [Lodders, 1998].

[40] The apparently lower value of $T_{e}$ for west Tharsis relative to Thaumasia is not as simple to interpret. The flexural signal from topography is set when a feature loads the lithosphere. Tharsis has had both loading and lithospheric rigidity vary over time to produce a complicated signal. The lack of a definitive difference in $T_{e}$ between the two halves of Tharsis is most likely due to the limitations in the analysis of admittance data as it assumes loading has occurred all at one time. Evidence suggests that the bulk of Tharsis was emplaced prior to the end of the Noachian. The orientations of Noachian tectonic features [Anderson et al., 2001] are consistent with models of elastic stresses using present-day topography implying that the extent of the topographic load in the Noachian was comparable to that at present [Banerdt and Golombek, 2000]. Further, the location and orientation of Noachian-age valley networks appear to have been influenced by the presence of Tharsis and its antipodal bulge in Arabia Terra [Phillips et al., 2001], and the preservation of magnetic anomalies in the Noachian terrains in the region indicate some volcanic construction occurred when the dynamo was still active [Johnson and Phillips, 2005]. These observations, along with our result of $T_{e}=81 \mathrm{~km}$ for west Tharsis, collectively imply that the long wavelength bulge of Tharsis is an ancient Noachian feature. However, the young surface ages on and around the shield volcanoes reveal that a long-lived history of volcanic construction has been sustained in the western portion of Tharsis into the relatively recent past. Further, large volcano formation is much more likely at 


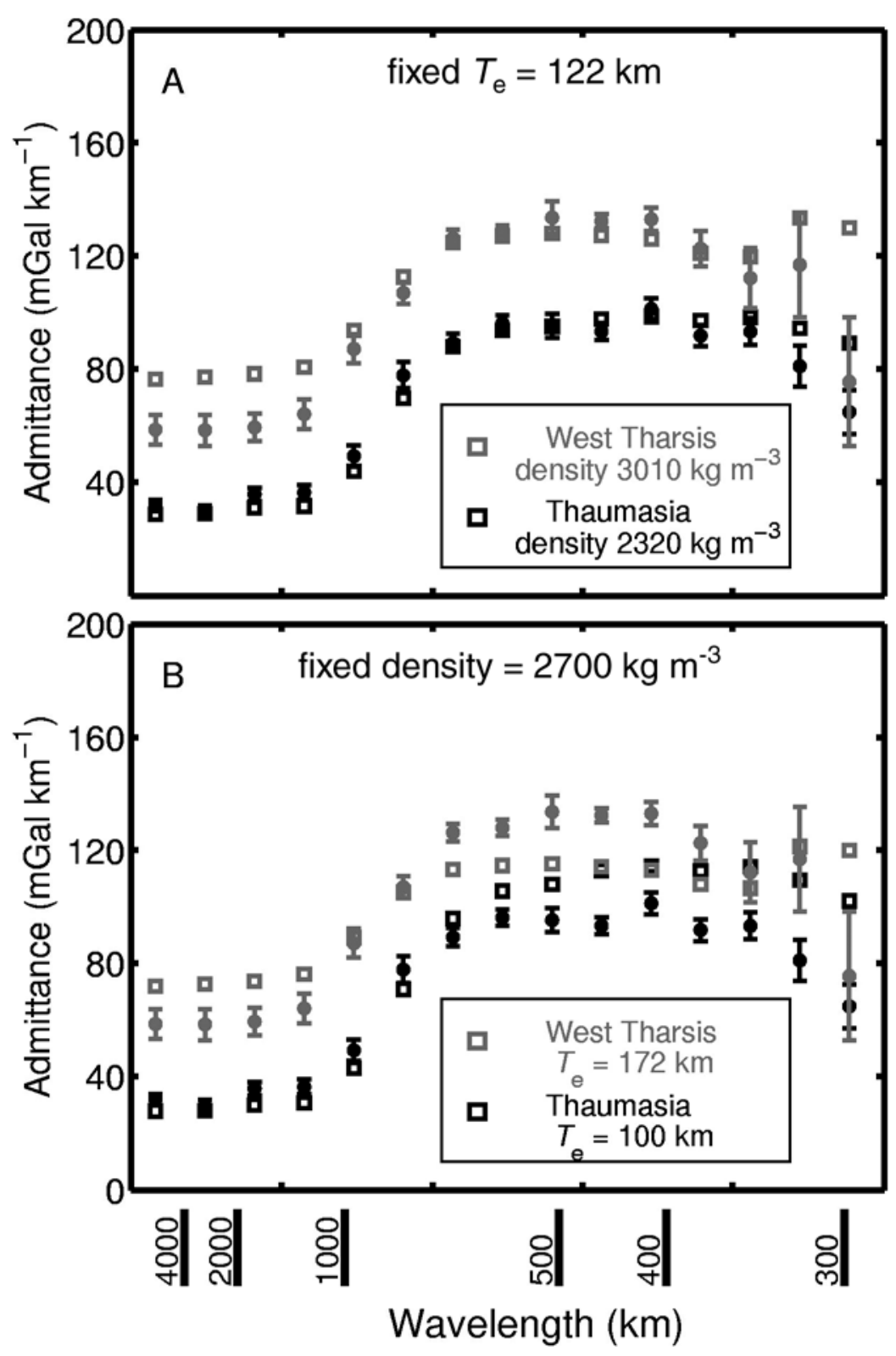

Figure 14. Observed admittance (solid circles) for Thaumasia (black) and west Tharsis (gray) with bestfit modeled admittances (squares). (A) $T_{\mathrm{e}}$ is held constant at $122 \mathrm{~km}$ for both regions. (B) Surface density is held constant at $2700 \mathrm{~kg} \mathrm{~m}^{-3}$ for both regions. The observed admittance values in the wavelength range 400-700 km strongly support the hypothesis that the two regions have different surface densities (see text).

larger $T_{e}$ values as low values result in high horizontal compressive stress that inhibits edifice growth $[M c$ Govern and Solomon, 1998]. The volcanoes therefore likely reflect a thick lithosphere and contribute power in the admittance at shorter wavelengths; their diameters are relatively small $(\sim 400 \mathrm{~km})$. This would provide a strong admittance signal at the short wavelengths from which the surface density is determined, while the flexural signal would remain somewhat ambiguous.

\subsection{Discussion}

[41] The progression in surfaces ages from the oldest, preserved in Thaumasia on the southeast margin of Tharsis, to the youngest, at Olympus Mons on the western margin, suggests there has been an alteration of the underlying convection since the Early Noachian resulting in a migration in volcanic activity away from Thaumasia leading to the preservation of the Noachian terrains observed in that region. This progression is evident in the crater counts. Figure 15A shows a histogram of the total number of craters with diameters $>10 \mathrm{~km}$ across Tharsis from the Martian crater catalog of Barlow [2000] starting with the Thaumasia study region of section $3.3 .1\left(240^{\circ}\right.$ to $320^{\circ} \mathrm{E},-60^{\circ}$ to $\left.5^{\circ} \mathrm{N}\right)$ and shifting the region of crater counting by $10^{\circ}$ north and west for each histogram bin ending with the study region of west Tharsis discussed in section $3.3 .2\left(200^{\circ}\right.$ to $280^{\circ} \mathrm{E}$, $-20^{\circ}$ to $45^{\circ} \mathrm{N}$ ). The decline in the number of craters westward, as would be expected, reflects the percentages 

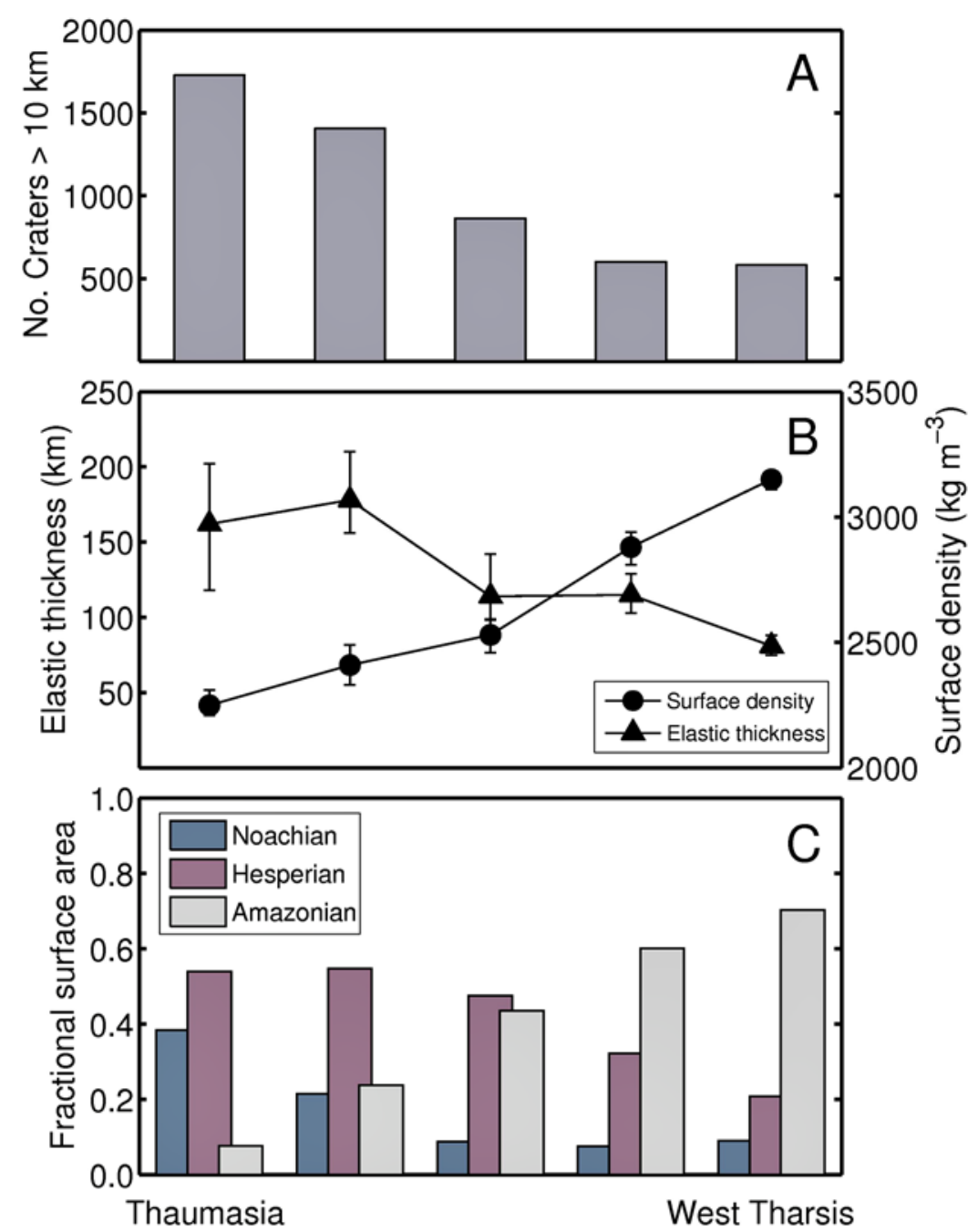

Figure 15. (A) Total number of craters $>10 \mathrm{~km}$ in diameter from the crater catalog of Barlow [2000] within five regions where the first histogram bin represents the Thaumasia study region described in the text, the last bin is that of the west Tharsis study region, and the three intermediate bins represent progressive shifts of $10^{\circ}$ longitude and latitude of the region of crater counts. (B) The best-fit elastic thickness (left axis) and surface density (right axis) as determined from admittance for each region. (C) The percent of Noachian, Hesperian, and Amazonian terrain in the five regions.

of Noachian, Hesperian, and Amazonian terrains (Figure 15C). The surface densities obtained from the admittance also mirror this surface age migration. Determining the admittance and best-fit model admittance for each area portrayed in the histogram bins of Figure 15, we find a progression from the lowest surface densities in Thaumasia, $2250 \mathrm{~kg}$ $\mathrm{m}^{-3}$, to the highest densities in west Tharsis, $3150 \mathrm{~kg} \mathrm{~m}^{-3}$. The near-surface crust of Thaumasia is either more porous from impacts during heavy bombardment and/or is composed of lower density sediments. The higher densities of west Tharsis are consistent with the densities of the SNC meteorites (basalts and ultramafic cumulates) and reflect a younger, less altered surface layer. The fact that the crater counts correlate with the densities implies that disruption of the surface layer by impacts, rather than differences in lithology, plays a dominant role in controlling the surface densities in this region. The elastic thicknesses however do not increase systematically with decreasing surface age and in fact west Tharsis yields a lower $T_{e}$ than Thaumasia. This suggests that the formation age of the topographic bulge of Tharsis cannot be inferred from surface ages and the younger units represent a veneer several $\mathrm{km}$ thick. This observation implies that the apparent migration of volcanism across Tharsis observed in the surface ages from east to west is due to a progressively greater confinement of the surface volcanism to the western margin of Tharsis (i.e., an asymmetric reduction in the areal extent of volcanism).

\subsection{Summary}

[42] The admittance of Thaumasia yields $T_{e}=162 \mathrm{~km}$. This value likely results from the admittance signal being dominated by large amplitude younger (Hesperian and later) features that are prevalent in the northern portion of Thaumasia and possibly the continued thermal subsidence of the plateau after the initial flexural signal of the Thaumasia Highlands was established. The admittance of the western half of Tharsis in comparison yields $T_{e}=81 \mathrm{~km}$. This implies the predominantly Amazonian surface ages of the 
region are relatively thin and the bulk of the topographic bulge was emplaced in the Noachian. Additionally, the volcanic edifices in west Tharsis have wavelengths generally shorter than $\sim 500 \mathrm{~km}$ and hence do not contribute to the flexural part of the admittance. The densities, on the other hand, show a progression from low to high that correlates with crater densities and the predominant surface ages for five regions crossing Tharsis with the lowest surface density found in Thaumasia, $2250 \mathrm{~kg} \mathrm{~m}^{-3}$, and the highest density in west Tharsis, $3150 \mathrm{~kg} \mathrm{~m}^{-3}$.

\section{Conclusions and Implications}

\subsection{Conclusions}

[43] Tharsis is the most dominant topographic feature on Mars next to the crustal dichotomy. Our admittance results are consistent with the bulk of the topography having been in place by the end of the Noachian, the first $\sim 700 \mathrm{Ma}$ after planetary accretion. The variety of surface ages in Tharsis, generally trending from the oldest in the southeast to the youngest at the western margin, span the entire observable geologic record of Mars revealing a prolonged volcanic history. We interpret the $T_{\mathrm{e}}$ values derived in this study to imply that the bulk of the bulge was formed relatively early in the planet's history irrespective of the observed age progression of the surface units. The age progression however, is reflected in the surface densities which are constrained by the shorter wavelengths in the admittance.

[44] We interpret Thaumasia to be an ancient volcanic plateau that was emplaced by the end of the Early Noachian. The observation that the flexural moat adjacent to the Thaumasia Highlands is buried by Late Noachian and Hesperian units, and analysis of the LOS acceleration profiles yielding $T_{e} \sim 20 \mathrm{~km}$, confirm that the southeast margin is the oldest preserved region of Tharsis. Making the simple assumption that $T_{e}$ corresponds to a depth to an isotherm $\left(\sim 650^{\circ} \mathrm{C}\right)$ [Zuber et al., 2000], and the temperature at the top of the mantle is similar to that of the Earth $\left(\sim 1300^{\circ} \mathrm{C}\right)$, implies the upper thermal boundary layer thickness of Mars in the stagnant lid convection regime was $\sim 34 \mathrm{~km}$ during the Early Noachian, consistent with thermal evolution models of Mars [e.g., Williams and Nimmo, 2004]. Other Noachian terrains of the southern highlands yield similar elastic thicknesses [Zuber et al., 2000; McKenzie et al., 2002; McGovern et al., 2004]. In addition, the existence of magnetic anomalies in the Thaumasia Highlands suggests that the volcanic construction was occurring while the Martian dynamo was still active in the Early Noachian [Johnson and Phillips, 2005]. The absence of crustal magnetic anomalies around the large impact basins of Hellas and Argyre imply that the dynamo had shut off by the time those impact events occurred, $\sim 4 \mathrm{Ga}$ [Acuña et al., 1999].

[45] We found top loading to be dominant (i.e., $F$ was never found to be $>1$ ). This supports the paradigm of Tharsis being largely the result of surface loading [Solomon and Head, 1982; Willemann and Turcotte, 1982] rather than resulting from uplift of thickened buoyant crust [Wise et al., 1979a, 1979b; Sleep and Phillips, 1979, 1985] or dynamic support from processes in the mantle [Hartmann, 1973; Phillips et al., 1973; Carr, 1974; Plescia and Saunders, 1980].
[46] These conclusions are consistent with the following general scenario:

[47] 1. Tharsis was largely the result of volcanic construction at the surface of Mars. Our admittance models were all dominantly top loading $(F<1)$.

[48] 2. Thaumasia is the remnant of a large igneous feature.

[49] 3. Thaumasia, and likely the bulk of the entire Tharsis bulge, was in place during the Noachian. We find $T_{e} \sim 20 \mathrm{~km}$ for the Thaumasia Highlands and the adjacent flexural moat filled with Late Noachian terrains indicating a very early formation age. For west Tharsis, $T_{e}=81 \mathrm{~km}$ indicating that in spite of the Amazonian age surface units, the underlying bulge is relatively old, however not necessarily as old as the Thaumasia Plateau.

[50] 4. Volcanic effusion rates were very high during the Early Noachian but quickly diminishing in the Late Noachian and Hesperian.

[51] 5. Volcanic activity persisted into the present in more localized regions confined to the western half of the province. The surface densities reflect the surface ages as relatively low densities were found in Thaumasia, $2250 \mathrm{~kg}$ $\mathrm{m}^{-3}$, and higher densities found for west Tharsis, $3150 \mathrm{~kg} \mathrm{~m}^{-3}$.

[52] 6. For Thaumasia, $T_{e}=162 \mathrm{~km}$ and may reflect thermal subsidence of the plateau as volcanism became confined westward, and the presence of younger topographic features with high amplitudes at flexural wavelengths (e.g., Valles Marineris).

[53] This scenario is consistent with thermal history models of Mars [e.g., Spohn et al., 2001; Williams and Nimmo, 2004] that predict rapid cooling of the planet's interior early in its history with more modest cooling through the Hesperian and Amazonian.

\subsection{Implications}

\subsubsection{Volume and Timing of Volcanics}

[54] The western hemisphere of Mars was dominated by volcanic construction during the Noachian. Thaumasia, interpreted here to be a volcanic plateau $\sim 10-20 \mathrm{~km}$ in thickness, was emplaced by the end of the Early Noachian. This represents $\sim 50-100$ million $\mathrm{km}^{3}$ of material (equivalent to $\mathrm{a} \sim 350-700 \mathrm{~m}$ global layer) having been produced within $\sim 500 \mathrm{Ma}$. Further, the $\sim 10 \mathrm{~km}$ sequence of rocks exposed in the walls of Valles Marineris that comprise the northern margin of the Thaumasia Plateau provides important compositional and structural information. The wall rocks are most likely to be predominantly flood basalts and layered igneous intrusives [McEwen et al., 1999; Williams et al., 2003], possibly interspersed with a sedimentary component on eruptive horizons or preexisting sedimentary rock entrained in the igneous matrix. The observation of basalt and olivine-rich basalts within the walls of the chasma from spectra obtained by Mars Odyssey THEMIS (Thermal Emission Imaging System) [Christensen et al., 2003], as well as olivine-rich and pyroxene-rich layers in the wall rock observed by the Mars Express OMEGA instrument [Mustard et al., 2005] substantiate this interpretation.

[55] These plateau rocks, capped by Hesperian and Late Noachian age units, represent the Noachian extrusive and intrusive igneous rocks that formed the plateau, attesting to the high effusion rates of the region during the Early 
Noachian. The wall rock of the chasma presents $\sim 30$ million $\mathrm{km}^{3}$ of directly observable volcanics [McEwen et al., 1999]. In comparison, Olympus Mons has a volume $\sim 7.5$ million $\mathrm{km}^{3}$ with surfaces ages spanning $\sim 1 \mathrm{Ga}$ and edifice construction presumably occurring over a longer time-scale. Phillips et al. [2001] found a nominal value of $T_{e}=100 \mathrm{~km}$ for the entirety of the Tharsis bulge. This indicates that $T_{e}$ increased rapidly to a value $\sim 100 \mathrm{~km}$ by the end of the Noachian epoch. Assuming $T_{\mathrm{e}}=100 \mathrm{~km}$, the topography of Tharsis and the volume of material filling the underlying flexural depression represents $\sim 300$ million $\mathrm{km}^{3}$ of volcanics erupted in $\sim 1 \mathrm{Ga}$ [Phillips et al., 2001]. This is the equivalent of a $\sim 2 \mathrm{~km}$ layer of volcanics spread out globally and corresponds to an effusion rate for Tharsis of $\sim 0.3 \mathrm{~km}^{3} \mathrm{yr}^{-1}$ during the Noachian, or $\sim 1.3$ times the rate of extrusive volcanism on Earth over the last $180 \mathrm{Ma}$ per unit area [Crisp, 1984].

\subsubsection{Coronae and Volcanics}

[56] The pattern of volcanism in Tharsis appears to have changed from voluminous large-scale $(1000 \mathrm{~s} \mathrm{~km})$ plateau building in the Noachian, to small-scale $(100 \mathrm{~s} \mathrm{~km})$ shield building by the Amazonian. For low values of $T_{e}$, large lithospheric deflections result in high levels of compressive stresses in a growing volcano that inhibit magma ascent to the summit [McGovern and Solomon, 1993, 1998]. Flexure in the volcano will result in rotation in the principal stresses induced in the load favoring horizontal propagation of magma outward from the summit to the flanks and thus areally extensive vent or sheet volcanism is favored. From this effect we conclude that the large shield volcanoes of Tharsis are the manifestation of volcanism occurring on lithosphere that has exceeded a critical value of $T_{e}$ for a given characteristic wavelength of upwelling beneath the lithosphere.

[57] This hypothesis is further supported by evidence that volcanoes on Venus are on average younger than coronae [McGovern and Solomon, 1998] and that transitional features observed on Venus, domical volcanoes with broad central depressions resulting from corona-like sagging, represent features emplaced on lithosphere exhibiting $T_{e}$ values near the critical value [Herrick et al., 2005]. Coronae, quasi-circular to circular volcano-tectonic features uniquely identified on Venus [Barsukov et al., 1986], may represent a manifestation of heat liberation on a single plate planet [Smrekar and Stofan, 1997; Jellinek et al., 2002]. Volcanism occurs throughout the process of corona formation and volcanic construction is likely to play a role in establishing their topography [Squyres et al., 1992; Stofan et al., 1992; Grindrod et al., 2005].

[58] Our interpretation of Thaumasia as a large igneous structure, and the large topographic bulge of Tharsis as an ancient feature resulting from volcanic construction, is consistent with widespread volcanism on a thin, weak lithosphere during the Noachian. As $T_{e}$ increased over time, and effusive volumes moderated, shield structures evolved as the predominant manifestation of volcanism. Our conclusions support the argument that $T_{e}$ plays a role in whether a corona or a volcano will form on a single plate planet. With Mars establishing a large $T_{e}$ quickly, it also explains why coronae, Thaumasia being a possible exception, are not observed on Mars today.
[59] Acknowledgments. We thank Alistair Crosby and Bruce Banerdt for their thoughtful reviews. Jean-Pierre Williams was supported by the California Institute of Technology through the O. K. Earl Postdoctoral Fellowship and the National Science Foundations Astronomy and Astrophysics Research Grants program (AST-0709151).

\section{References}

Acuña, M. H., et al. (1999), Global distribution of crustal magnetization discovered by the Mars Global Surveyor MAG/ER experiment, Science, 284(5415), 790-793.

Albee, A. L., R. E. Arvidson, F. D. Palluconi, and T. Thorpe (2001), Overview of the Mars Global Surveyor mission, J. Geophys. Res., 106(E10), $23,291-23,316$

Anderson, R. C., J. M. Dohm, M. P. Golombek, A. F. C. Haldemann, B. J. Franklin, K. L. Tanaka, J. Lias, Juan, and B. Peer (2001), Primary centers and secondary concentrations of tectonic activity through time in the western hemisphere of Mars, J. Geophys. Res., 106(E9), 20,563-20,585.

Banerdt, B. W., M. P. Golombek, and K. L. Tanaka (1992), Stress and tectonics on Mars, in Mars, edited by H. Kieffer et al., pp. 249-297, Univ. of Arizona Press, Tucson, Ariz.

Banerdt, B. W., and M. P. Golombek (2000), Tectonics of the Tharsis region of Mars: Insights from MGS topography and gravity, Lunar Planet. Sci. Conf., XXXI, abstract 2038.

Barlow, N. G. (2000), Updates to the "Catalog of large Martian impact craters", Lunar Planet. Sci. Conf., XXXI, Abstract 1475.

Barnett, D. N., F. Nimmo, and D. McKenzie (2000), Elastic thickness estimates for Venus using line of sight accelerations from Magellan cycle 5, Icarus, 146(2), 404-419.

Barsukov, V. L., et al. (1986), The geology and geomorphology of the Venus surface as revealed by the radar images obtained by Veneras 15 and Veneras 16, J. Geophys. Res., 91(B4), D378-D398.

Belleguic, V., P. Lognonne, and M. Wieczorek (2005), Constraints on the Martian lithosphere from gravity and topography data, J. Geophys. Res., 110, E11005, doi:10.1029/2005JE002437.

Boynton, W. V., et al. (2002), Distribution of hydrogen in the near surface of Mars: Evidence for subsurface ice deposits, Science, 297(5578), 81 85.

Carr, M. H. (1974), Tectonism and volcanism of Tharsis region of Mars, J. Geophys. Res., 79(26), 3943-3949.

Christensen, P. R., et al. (2003), Morphology and composition of the surface of Mars: Mars Odyssey THEMIS results, Science, 300(5628), 2056-2061

Christensen, P. R., et al. (2004), The Thermal Emission Imaging System (THEMIS) for the Mars 2001 Odyssey Mission, Space Sci. Rev., 110, $85-130$.

Crisp, J. A. (1984), Rates of magma emplacement and volcanic output, J. Volcanol. Geotherm. Res., 20(3-4), 177-211.

Crosby, A. G. (2007), An assessment of the accuracy of admittance and coherence estimates using synthetic data, Geophys. J. Int., 171, 25-54.

Dohm, J. M., J. C. Ferris, V. R. Baker, R. C. Anderson, T. M. Hare, R. G. Strom, N. G. Barlow, K. L. Tanaka, J. E. Klemaszewski, and D. H. Scott (2001), Ancient drainage basin of the Tharsis region, Mars: Potential source for outflow channel systems and putative oceans or paleolakes, J. Geophys. Res., 106(E12), 32,943-32,958.

Dombard, A. J., M. L. Searls, and R. J. Phillips (2004), An alternative explanation for the "Buried Channels" on Mars: The gravity signal from a sharp boundary on partially compensated, long-wavelength topography, Geophys. Res. Lett., 31, L05701, doi:10.1029/2003GL019162.

Edgett, K. S. (2005), The sedimentary rocks of Sinus Meridiani: Five key observations from data acquired by Mars Global Surveyor and Mars Odyssey orbiters, Mars, 1, 5-58.

Esposito, P. B., W. B. Banerdt, G. F. Lindal, W. L. Sjogren, M. A. Slade, B. G. Bills, D. E. Smith, and G. Balmino (1992), Gravity and topography, in Mars, edited by H. Kieffer et al., pp. 209-248, Univ. of Arizona Press, Tucson, Ariz.

Feldman, W. C., et al. (2002), Global distribution of neutrons from Mars: Results from Mars Odyssey, Science, 297(5578), 75-78.

Forsyth, D. W. (1985), Subsurface loading and estimates of the flexural rigidity of continental lithosphere, J. Geophys. Res., 90(B14), 12,62312,632 .

Grindrod, P. M., F. Nimmo, E. R. Stofan, and J. E. Guest (2005), Strain at radially fractured centers on Venus, J. Geophys. Res., 110, E12002, doi:10.1029/2005JE002416

Hartmann, W. K. (1973), Martian surface and crust-review and synthesis, Icarus, 19(4), 550-575.

Hartmann, W. K. (1999), Martian cratering VI: Crater count isochrons and evidence for recent volcanism from Mars Global Surveyor, Meteorit. Planet. Sci., 34(2), 167-177.

Hartmann, W. K. (2005), Martian cratering 8: Isochron refinement and the chronology of Mars, Icarus, 174(2), 294-320. 
Hartmann, W. K., and G. Neukum (2001), Cratering chronology and the evolution of Mars, Space Sci. Rev., 96(1-4), 165-194.

Herrick, R. R., J. Dufek, and P. J. McGovern (2005), Evolution of large shield volcanoes on Venus, J. Geophys. Res., 110, E01002, doi:10.1029/ 2004JE002283.

Janle, P., and D. Jannsen (1986), Isostatic gravity and elastic bending models of Olympus Mons, Mars, Ann. Geophys., Ser. B, 4(5), 537-546.

Jellinek, A. M., A. Lenardic, and M. Manga (2002), The influence of interior mantle temperature on the structure of plumes: Heads for Venus, tails for the Earth, Geophys. Res. Lett., 29(11), 1532, doi:10.1029/ 2001 GL014624.

Johnson, C. L., and R. J. Phillips (2005), Evolution of the Tharsis region of Mars: Insights from magnetic field observations, Earth Planet. Sci. Lett., 230(3-4), 241-254.

Konopliv, A. S., C. F. Yoder, E. M. Standish, D. N. Yuan, and W. L. Sjogren (2006), A global solution for the Mars static and seasonal gravity, Mars orientation, Phobos and Deimos masses, and Mars ephemeris, Icarus, 182(1), 23-50.

Lemoine, F. G., D. E. Smith, D. D. Rowlands, M. T. Zuber, G. A. Neumann, D. S. Chinn, and D. E. Pavlis (2001), An improved solution of the gravity field of Mars (GMM-2B) from Mars Global Surveyor, J. Geophys. Res., 106(E10), 23,359-23,376.

Lodders, K. (1998), A survey of shergottite, nakhlite and chassigny meteorites whole-rock compositions, Meteorit. Planet. Sci., 33(4), A183-A190.

Longhi, J., E. Knittle, J. R. Holloway, and H. Wänke (1992), The bulk composition, mineralogy and internal structure of Mars, in Mars, edited by H. Kieffer et al., pp. 184-208, Univ. of Arizona Press, Tuscon, Ariz.

Lucchitta, B. K., A. S. McEwen, G. D. Clow, P. E. Geissler, R. B. Singer, R. A. Schultz, and S. W. Squyres (1992), The canyon system on Mars, in Mars, edited by H. Kieffer et al., pp. 453-492, Univ. of Arizona Press, Tucson, Ariz.

Malin, M. C. (1986), Density of Martian north polar layered deposits: Implications for composition, Geophys. Res. Lett., 13(5), 444-447.

Malin, M. C., and K. S. Edgett (2000), Sedimentary rocks of early Mars, Science, 290(5498), 1927-1937.

Malin, M. C., and K. S. Edgett (2001), Mars Global Surveyor Mars Orbiter Camera: Interplanetary cruise through primary mission, J. Geophys. Res., 106(E10), 23,429-23,570.

McEwen, A. S., M. C. Malin, M. H. Carr, and W. K. Hartmann (1999), Voluminous volcanism on early Mars revealed in Valles Marineris, Nature, 397(6720), 584-586

McGovern, P. J., and S. C. Solomon (1993), State of stress, faulting, and eruption characteristics of large volcanoes on Mars, J. Geophys. Res., 98(E12), 23,553-23,579.

McGovern, P. J., and S. C. Solomon (1998), Growth of large volcanoes on Venus: Mechanical models and implications for structural evolution, J. Geophys. Res., 103(E5), 11,071-11,101.

McGovern, P. J., S. C. Solomon, D. E. Smith, M. T. Zuber, M. Simons, M. A. Wieczorek, R. J. Phillips, G. A. Neumann, O. Aharonson, and J. W. Head (2002), Localized gravity/topography admittance and correlation spectra on Mars: Implications for regional and global evolution, J. Geophys. Res., 107(E12), 5136, doi:10.1029/2002JE001854

McGovern, P. J., S. C. Solomon, D. E. Smith, M. T. Zuber, M. Simons, M. A. Wieczorek, R. J. Phillips, G. A. Neumann, O. Aharonson, and J. W Head (2004), Correction to "Localized gravity/topography admittance and correlation spectra on Mars: Implications for regional and global evolution", J. Geophys. Res., 109, E07007, doi:10.1029/2004JE002286.

McKenzie, D. (1994), The relationship between topography and gravity on Earth and Venus, Icarus, 112(1), 55-88.

McKenzie, D. (2003), Estimating $T_{\mathrm{e}}$ in the presence of internal loads, J. Geophys. Res., 108(B9), 2438, doi:10.1029/2002JB001766.

McKenzie, D., and D. Fairhead (1997), Estimates of the effective elastic thickness of the continental lithosphere from Bouguer and free air gravity anomalies, J. Geophys. Res., 102(B12), 27,523-27,552.

McKenzie, D., and F. Nimmo (1997), Elastic thickness estimates for Venus from line of sight accelerations, Icarus, 130(1), 198-216.

McKenzie, D., D. N. Barnett, and D.-N. Yuan (2002), The relationship between Martian gravity and topography, Earth Planet. Sci. Lett. 195(1-2), 1-16.

McSween, H. Y. (1994), What have we learned about Mars from SNC meteorites, Meteoritics, 29(6), 757-779.

Mustard, J. F., F. Poulet, A. Gendrin, J.-P. Bibring, Y. Langevin, B. Gondet, N. Mangold, G. Bellucci, and F. Altieri (2005), Olivine and pyroxene, diversity in the crust of Mars, Science, 307(5715), 1594-1597.

Neukum, G., and The HRSC Co-Investigator Team, et al. (2004), Recent and episodic volcanic and glacial activity on Mars revealed by the High Resolution Stereo Camera, Nature, 432(7020), 971-979.

Neumann, G. A., M. T. Zuber, M. A. Wieczorek, P. J. McGovern, F. G. Lemoine, and D. E. Smith (2004), Crustal structure of Mars from gravity and topography, J. Geophys. Res., 109, E08002, doi:10.1029/ 2004JE002262

Nimmo, F. (2002), Admittance estimates of mean crustal thickness and density at the Martian hemispheric dichotomy, J. Geophys. Res., 107(E11), 5117, doi:10.1029/2000JE001488.

Nimmo, F., and D. J. Stevenson (2001), Estimates of Martian crustal thickness from viscous relaxation of topography, J. Geophys. Res., 106(E3), $5085-5098$

Nimmo, F., and K. Tanaka (2005), Early crustal evolution of mars, Annu. Rev. Earth Planet. Sci., 33, 133-161.

Pérez-Gussinyé, M., A. R. Lowry, A. B. Watts, and I. Velicogna (2004), On the recovery of effective elastic thickness using spectral methods: Examples from synthetic data and from the Fennoscandian Shield, J. Geophys. Res., 109, B10409, doi:10.1029/2003JB002788.

Phillips, P. J., et al. (2001), Ancient geodynamics and global-scale hydrology on Mars, Science, 291(5513), 2587-2591.

Phillips, R. J., R. S. Saunders, and J. E. Conel (1973), Mars: Crustal structure inferred from Bouguer gravity anomalies, J. Geophys. Res., $78(23), 4815-4820$

Plescia, J. B., and R. S. Saunders (1980), Estimation of the thickness of the Tharsis lava flows and implications for the nature of the topography of the Tharsis plateau, Lunar Planet. Sci. Conf., XI, 2423-2436.

Press, W. H., S. A. Teukolsky, W. T. Vetterling, and B. P. Flannery (1992), Numerical Recipes in Fortran, 2nd ed., 933 pp., Cambridge Univ. Press, New York.

Scott, D. H., and K. L. Tanaka (1986), Geologic Map of the Western Equatorial Region of Mars, scale 1:15,000,000. U.S.G.S. Misc. Inv. Series Map I-1082-A.

Simons, F. J., M. T. Zuber, and J. Korenaga (2000), Isostatic response of the Australian lithosphere: Estimation of effective elastic thickness and anisotropy using multitaper spectral analysis, J. Geophys. Res., 105(B8), $19,163-19,184$

Sjogren, W. L., J. Lorell, L. Wong, and W. Downs (1975), Mars gravity field based on a short-arc technique, J. Geophys. Res., 80(20), 28992908

Sleep, N. H., and R. J. Phillips (1979), An isostatic model for the Tharsis province, Mars, Geophys. Res. Lett., 6(10), 803-806.

Sleep, N. H., and R. J. Phillips (1985), Gravity and lithospheric stress on the terrestrial planets with reference to the Tharsis region of Mars, J. Geophys. Res., 90(B6), 4469-4489.

Smith, D. E., et al. (1999a), The gravity field of Mars: Results from Mars global surveyor, Science, 286(5437), 94-97.

Smith, D. E., W. L. Sjogren, G. L. Tyler, G. Balmino, F. G. Lemoine, and A. S. Konopliv (1999b), The global topography of Mars and implications for surface evolution, Science, 284(5419), 1495-1503.

Smrekar, S. E., and E. R. Stofan (1997), Corona formation and heat loss on Venus by coupled upwelling and delamination, Science, 277(5330), $1289-1294$

Solomon, S. C., and J. W. Head (1982), Evolution of the Tharsis province of Mars: The importance of heterogeneous lithospheric thickness and volcanic construction, J. Geophys. Res., 87(B12), 9755-9774.

Spohn, T., F. Sohl, and D. Breuer (2001), Geophysical constraints on the evolution of Mars, Space Sci. Rev., 96(1-4), 231-262.

Squyres, S. W., D. M. Janes, G. Baer, D. L. Bindschadler, G. Schubert, V. L. Sharpton, and E. R. Stofan (1992), The morphology and evolution of coronae on Venus, J. Geophys. Res., 97(E8), 13,611-13,634.

Stofan, E. R., V. L. Sharpton, G. Schubert, G. Baer, D. L. Bindschadler, D. M. Janes, and S. W. Squyres (1992), Global distribution and characteristics of coronae and related features on Venus: Implications for origin and relation to mantle processes, J. Geophys. Res., 97(E8), 13,34713,378

Tanaka, K. L., and P. A. Davis (1988), Tectonic history of the Syria Planum province of Mars, J. Geophys. Res., 93(B12), 14,893-14,917.

Tanaka, K. L., J. M. Dohm, J. H. Lias, and T. M. Hare (1998), Erosional valleys in the Thaumasia region of Mars: Hydrothermal and seismic origins, J. Geophys. Res., 103(E13), 31,407-31,419.

Thomsen, D. J. (1982), Spectrum estimation and harmonic analysis, in Proc. IEEE, 70, 1055-1096.

Turcotte, D. L., and G. Schubert (2002), Geodynamics, Cambridge Univ. Press, New York.

Turcotte, D. L., R. J. Willeman, W. F. Haxby, and J. Norberry (1981), Role of membrane stresses in the support of planetary topography, J. Geophys. Res., 86(B5), 3951-3959.

Turcotte, D. L., R. Shcherbakov, B. D. Malamud, and A. B. Kucinskas (2002), Is the Martian crust also the Martian elastic lithosphere?, J. Geophys. Res., 107(E11), 5091, doi:10.1029/2001JE001594.

Tyler, G. L., G. Balmino, D. P. Hinson, W. L. Sjogren, D. E. Smith, R. A Simpson, S. W. Asmar, P. Priest, and J. D. Twicken (2001), Radio science observations with Mars Global Surveyor: Orbit insertion through one Mars year in mapping orbit, J. Geophys. Res., 106(E10), 23,327-23,348. 
Watts, A. B. (2001), Isostasy and Fluxure of the Lithosphere, Cambridge Univ. Press, New York.

Watts, A. B., and E. B. Burov (2003), Lithospheric strength and its relationship to the elastic and seismogenic layer thickness, Earth Planet. Sci. Lett., 203, 113-131.

Wieczorek, M. A., and F. J. Simons (2005), Localized spectral analysis on the sphere, Geophys. J. Int., 160, 1-23.

Wieczorek, M. A., and M. T. Zuber (2004), Thickness of the Martian crust: Improved constraints from geoid-to-topography ratios, J. Geophys. Res., 109, E01009, doi:10.1029/2003JE002153.

Willemann, R. J., and D. L. Turcotte (1982), The role of lithospheric stress in the support of the Tharsis rise, J. Geophys. Res., 87(B12), 9793-9801.

Williams, J. P., and F. Nimmo (2004), Thermal evolution of the Martian core: Implications for an early dynamo, Geology, 32(2), 97-100.

Williams, J. P., D. A. Paige, and C. E. Manning (2003), Layering in the wall rock of Valles Marineris: Intrusive and extrusive magmatism, Geophys. Res. Lett., 30(12), 1623, doi:10.1029/2003GL017662.

Williams, J. P., W. B. Moore, and F. Nimmo (2004), The formation of Tharsis in the Noachian: What the line-of-sight gravity is telling us, 2nd Conf. Early Mars: Geologic, Hydrologic, and Climate Evolution and the Implication for Life, Abstract \#8054, Lunar Planetary Institute, Jackson Hole, Wyo, 11-15 October.
Wise, D. U., M. P. Golombek, and G. E. McGill (1979a), Tharsis province of Mars-Geologic sequence, geometry, and a deformation mechanism, Icarus, 38(3), 456-472.

Wise, D. U., M. P. Golombek, and G. E. McGill (1979b), Tectonic evolution of Mars, J. Geophys. Res., 84(B14), 7934-7939.

Yuan, D. N., W. J. Sjogren, A. S. Konopliv, and A. B. Kucinskas (2001), Gravity field of Mars: A 75th degree and order model, J. Geophys. Res., 106(E10), 23,377-23,401.

Zuber, M. T., D. E. Smith, S. C. Solomon, D. O. Muhleman, J. W. Head, J. B. Gravin, J. B. Abshire, and J. L. Bufton (1992), The Mars Observer Laser Altimeter investigation, J. Geophys. Res., 97(E5), 7781-7797.

Zuber, M. T., et al. (2000), Internal structure and early thermal evolution of Mars from Mars Global Surveyor topography and gravity, Science, 287(5459), 1788-1793

W. B. Moore and D. A. Paige, Department of Earth and Space Sciences, University of California, Los Angeles, 595 Charles Young Drive East, Box 951567, Los Angeles, CA 90095-1567, USA.

F. Nimmo, Department of Earth Sciences, University of California, Santa Cruz, Santa Cruz, CA 95064, USA.

J.-P. Williams, Division of Geological and Planetary Sciences, California Institute of Technology, MC 150-21, Pasadena, CA 91125, USA. (jpierre@gps.caltech.edu) 